International Journal of Engineering \& Technology, $7(2.20)(2018) 367-383$
International Journal of Engineering \& Technology
SPC
Website: www.sciencepubco.com/index.php/IJET
Research paper

\title{
Optimization of UWB Array Antenna for Bio-Medical Applications Using Cuckoo Search Algorithm
}

\author{
K. Rajkamal ${ }^{1}$, Govardhani.Immadi ${ }^{2}$ \\ 1. Research Scholar, Dept of ECE K L E F, Vaddeswaram, Guntur, A.P, India. \\ ${ }^{1}$ Associate Professor, Dept of ECE, Guntur Engineering College, Guntur, A.P, India. \\ ${ }^{2}$ Professor Department of ECE, KL E F, Vaddeswaram, Guntur, A.P, India.
}

\begin{abstract}
A four-element microstrip antenna array is designed in which the array is made using Wilkinson power dividers and four identical patch antenna elements. The elements of the designed array are perfectly developed to get a constant gain and have a compact size against the frequency. Using the microstrip technology equipment a prototype can be build to enhance the directivity, return loss and also its return loss and radiation pattern. The antenna array that is put forth here comprises of two major parts which are the array of the antennas and also its power network. In many of the important applications like biomedical, communication and also radio frequency applications the power divider plays a crucial role. Power dividers also function as the power networks of the array of antennas. An equal division power divider is generally required to synthesize the radiation pattern. Here a very new design for a power splitter having the same square sector of four ports and also its application is also presented. Techniques like insertion and also insertion fitting techniques were employed to adjust or alter the phase and amplitude of the signals that are exiting each branch of the power divider. The impedances of the branches are adjusted according to the required power ratio by using the pairing techniques. Electromagnetic Solvers which are based on MOM used in the design process. The parameters using which the power divider is made up of is the dielectric constant Er=4.3,loss tangent of 0.02 and height of $1.6 \mathrm{~mm}$. Along with the design of the ultra wide band antenna is also designed. Finally some of the optimization techniques such as the fly flight algorithm, cuckoo search algorithm, spring cuckoo algorithm for reducing mutual coupling and improving antenna parameters such as return loss, gain pattern, directivity and radiation. The experimental measurements are made using the network vector analyzer. A good agreement was found between the measurements and the results of the simulation.
\end{abstract}

Keywords: Rectangular Patch, Antenna array, Wilkinson power divider, UWB Antenna, UWB Array, optimization techniques.

\section{Introduction}

\subsection{UWB}

Ultra-wide band (UWB) technology is an ideal candidate for lowpower, low-cost, high-speed, short-range wireless communication systems [3]. According to the Report and Order of the Federal Communications Commission (FCC) of 2002 for unlicensed uses of UWB devices within the frequency band $3.1-10.6 \mathrm{GHz}$ [5]. The UWB signal is defined as a signal having a fractional bandwidth greater than $20 \%$ of the center frequency. The ultra wide bandwidth of the system makes the design of the antenna a new challenge. This is due to the fact that fading and multipath interference become more evident than in the narrow band system [6]. To overcome this phenomenon, smart antennas use antenna arrays as one of the possible solutions, a multi-objective optimization for the set of UWB antennas in the indoor environment [4].

\subsection{Array Antenna}

The antennas can be classified as a single element or array antennas [12]. The antennas of a single element can be omnidirectional or directional. Directional antennas have a maximum gain for the addresses of the user and less in others
[14]. Antenna arrays can be classified as in-phase matrices or adaptive arrays [7]. A phased array antenna system uses a matrix of omnidirectional or simple directional element antennas and combines the signal induced in the antennas to form a array output [16].

\subsection{Wilkinson Power Divider}

Power dividers are critical segments of a few microwave and millimeter wave circuits and furthermore an integral part of the antenna array power supply network [8]. They are basically power dividers as they divide the power, from input to the output ports, into required ratio and the same circuits can also be used as power combiners when used in reverse direction [9]. They play a vital role in various RF and communication applications such as in building wireless communication systems, power amplifiers, transmission line fault testing ratio measurements, test equipment's and also in signal processing applications [15]. Resistive Type, T-Junctions and Wilkinson Power Dividers are conventional three types of available power dividers [19]. Resistive type and T-junction type are the smallest preferred power dividers due to the reason that a poor isolation is observed between the output ports in comparison with Wilkinson power divider. If matched at all ports, is almost lossless and gives high isolation between output ports, however, if any mismatch occurs, 
The reflected power is dissipated through the isolation resistor [20]. This makes Wilkinson power divider is a perfect choice for power division [21].

\subsection{Optimization}

Most design optimization problems in engineering are often highly non-linear, and involve many different design variables under complex constraints. These constraints can be written as simple limits, such as the ranges of material properties, or as nonlinear relationships that include maximum voltage, maximum deflection, minimum load capacity, and geometric configuration. Such non-linearity often results in a multimodal response landscape. Subsequently, local search algorithms such as hill climbing and Nelder-Mead downhill simplex are not suitable, only global algorithms should be used to obtain optimal solutions (Deb 1995, Arora 1989, Yang 2005, Yang 2008). Modern metaheuristic algorithms have been developed with the aim of carrying out a global search, the typical examples are genetic algorithms (Glodberg 1989), particle swarm optimization (PSO) (Kennedy and Eberhart 1995, Kennedy et al 2001). The effectiveness of metaheuristic algorithms can be attributed to the fact that they mimic the best characteristics of nature, especially the selection of the most appropriate in biological systems that have evolved by natural selection over millions of years.Two important characteristics of metaheuristics are intensification and diversification (Blum and Roli 2003, Gazi and Passino 2004, Yang 2009). The intensification is intended to find the best current solutions and select the best candidates or solutions, while diversification ensures that the algorithm can explore the search space more efficiently, often by randomization. Recently, a new metaheuristic search algorithm, called Cuckoo Search (CS), has been developed by Yang and Deb (2009). Preliminary studies show that it is very promising and could overcome existing algorithms, such as PSO. In this document, we will study CS and validate it against the test functions, including the stochastic test functions. Then, we will apply it to solve design optimization problems in engineering. Finally, we will discuss the unique characteristics of Cuckoo Search and propose topics for future studies.

\subsection{Cuckoo Search}

To describe the search for the cuckoo more clearly, let's briefly review the interesting breed behavior of certain cuckoo species.

\subsubsection{Cuckoo Breeding Behavior}

Cuckoo are fascinating birds, not just due to the lovely sounds they make, yet in addition due to their repropagation strategy. A few animal varieties, for example, the ani and Guira cuckoos, lay their eggs in common homes, in spite of the fact that they can wipe out the eggs of others to build the likelihood of bring forth of their own eggs (Payne et al 2005).A good number of species are dedicated to the parasitism of forced breeding when they lay their eggs in the nests of other host birds (often other species). There are three basic types of brood parasitism: parasitism of intraspecific breeding, cooperative reproduction and nest capture. Some host birds may have direct conflict with intrusive cuckoos [11].On the off chance that a host winged creature finds that the eggs are not his property, he will toss these outsider eggs or basically leave his home and construct another home elsewhere. Some cuckoo species, for example, the parasitic rearing Tapera of the New World have developed such that female parasites are regularly extremely had practical experience in emulating the shading and example of the eggs of a couple of picked have The permittivity of a substance is usually given comparative to that of free space which is known as relative permittivity or dielectric constant $€$ r. Here we using FR-4 with $\epsilon r=4.3, \delta=0.025$ species (Payne et al 2005 ). This decreases the probability of their eggs being relinquished and along these lines expands their reproductivity. What's more, the egg-laying time of a few animal types is additionally shocking. Parasitic cuckoos regularly pick a home where the host feathered creature has quite recently laid its own eggs. As a rule, the cuckoo eggs bring forth somewhat sooner than their host eggs. Once the main cuckoo is brooded, the principal natural move to be made is to remove the host's eggs by indiscriminately driving the eggs out of the home, which builds the segment of the cuckoo chicken's sustenance given by its host feathered creature (Payne et al. 2005). Concentrates additionally demonstrate that an adorable chick can likewise mirror the call of host chicks to access all the more sustaining open doors [2].

\subsubsection{Levy Flights}

In nature, animals seek food in a random or quasi-random way, animals seek food randomly or quasi-randomly. In general, the feeding route of an animal is, electively, a random walk because the next movement is based on the current location / status and the probability of transition to the next location. The direction you choose depends implicitly on a probability that can be modeled mathematically. For example, several studies have shown that the behavior of many animals and insects has demonstrated the typical characteristics of Levy flights (Brown et al 2007, Reynods and Frye 2007, Pavlyukevich 2007). A recent study by Reynolds and Frye (2007) shows that fruit flies or Drosophila melanogaster explore their landscape using a series of straight flight paths punctuated by a sudden turn of 900 degrees, leading to an intermittent search pattern without Levy-flight style scales. Studies on human behavior, such as the hunter-gatherer search patterns Ju / hoansi, also show the typical characteristic of Levy flights. Even light can be related to Levy's flights (Barthelemy et al 2008). Subsequently, this behavior has been applied to optimization and optimal search, and preliminary results show its promising capacity (Shlesinger 2006, Pavlyukevich 2007).

\subsubsection{Cuckoo Search Idealized Rules}

To simplify when describing our new cuckoo search (Yang and Deb 2009), we now use the following three idealized rules:

- Each cuckoo lays one egg at a time, and dumps it in a randomly chosen nest;

- The best nests with high quality of eggs (solutions) will carry over to the next generations;

- The number of available host nests is fixed, and a host can discover an alien egg with a probability $\mathrm{p}_{\mathrm{a}} \in[0,1]$. In this case, the host bird can either throw the egg away or abandon the nest so as to build a completely new nest in anew location.

In Section II, our system description is presented. Several numerical results are included in Section III. Finally, the conclusion is drawn in section IV.

\section{Antenna Design}

\subsection{Substrate Materials Selection}

Table 1: Substrate materials used for proposed designs

\begin{tabular}{|c|c|c|c|}
\hline $\begin{array}{c}\text { Materials } \\
\text { used }\end{array}$ & Dielectric constant & $\begin{array}{c}\text { Thickness } \\
(\mathbf{m m})\end{array}$ & $\begin{array}{c}\text { Loss } \\
\text { tangent }\end{array}$ \\
\hline FR-4 & 4.3 & 1.6 & 0.025 \\
\hline
\end{tabular}

is used asantenna substrate. Selection of material for designing the antenna is unique in this paper. WhereasFR-4 is the primary Insulating backbone upon which the huge majority of rigid printed circuitboards (PCBs) are produced. 
In this work, first considering the Basic U slot CPW antenna is as shown in fig. 1 and their dimensions are included in Table 2. The designing and simulations are carried out in MOM based CST Microwave Studio. With the substrate material properties are shown in Table 1 and the radiating element used is copper and Results are discussed in section III

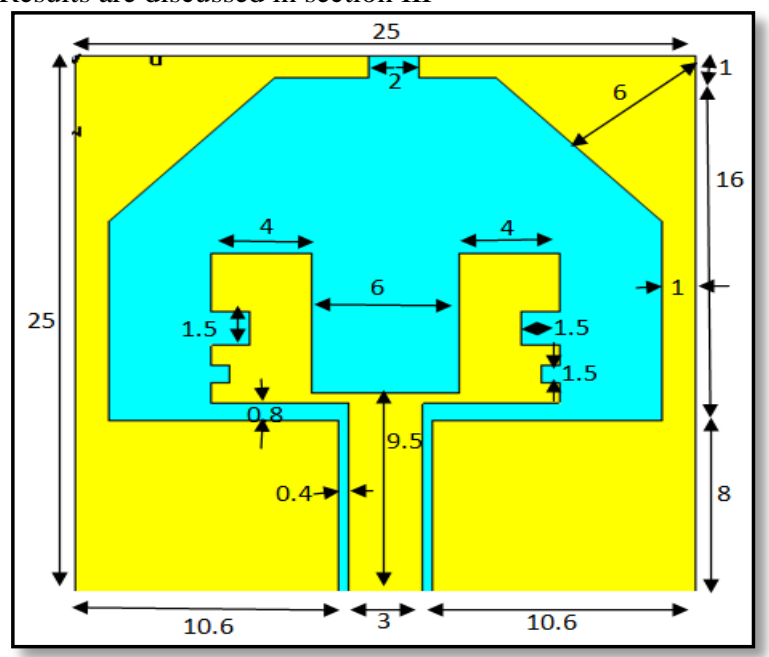

Fig.1:Proposed U-slot antenna

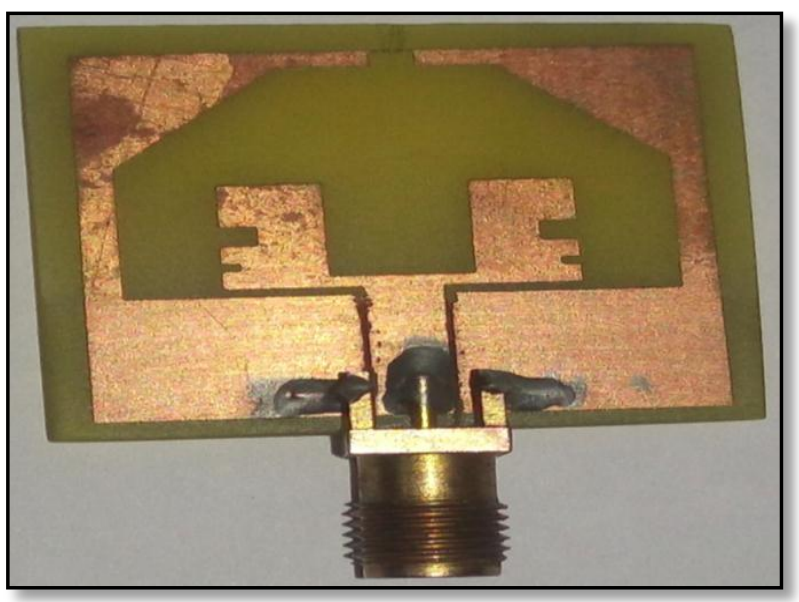

Fig. 2: Prototype of Proposed U-Slot antenna

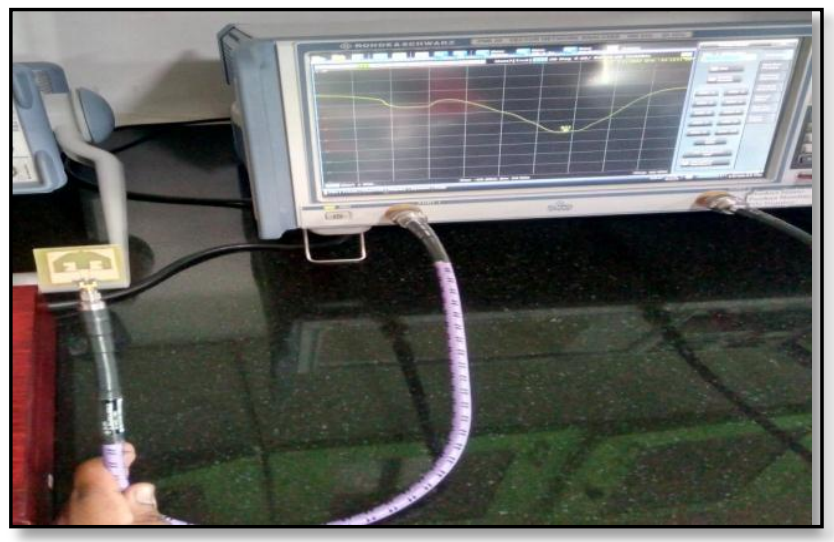

Fig .3: Testing Arrangement of Proposed U-Slot
Table 2: Dimensions of the U slot antenna

\begin{tabular}{|c|c|}
\hline Dimension & Value (mm) \\
\hline $\mathrm{L}$ & 25 \\
\hline $\mathrm{W}$ & 25 \\
\hline $\mathrm{W}_{1}$ & 10.6 \\
\hline $\mathrm{L}_{1}$ & 1 \\
\hline $\mathrm{L}_{2}$ & 16 \\
\hline $\mathrm{L}_{3}$ & 8 \\
\hline $\mathrm{W}_{2}$ & 1 \\
\hline $\mathrm{W}_{\mathrm{p} 1}$ & 4 \\
\hline $\mathrm{g}_{1}$ & 0.4 \\
\hline $\mathrm{g}_{2}$ & 0.8 \\
\hline $\mathrm{L}_{\mathrm{d}}$ & 6 \\
\hline $\mathrm{L}_{2}$ & 7 \\
\hline $\mathrm{L}_{\mathrm{f}}$ & 9.5 \\
\hline $\mathrm{W}_{\mathrm{f}}$ & 3 \\
\hline $\mathrm{H}$ & 1.6 \\
\hline & \\
\hline & \\
\hline
\end{tabular}

\subsection{X2 Array Antenna Implementation}

The main purpose of implementation of array is to enhance the Gain, Directivity and radiation pattern for achieving of these three parameters we will implement $1 \mathrm{X} 2$ proposed array antenna shown in Fig.4. Length and width of array antenna is $50 \times 25 \mathrm{X} 1.6 \mathrm{~mm}^{2}$, FR-4 with $\epsilon r=4.3, \delta=0.025$ is used asantenna substrate and results are disused in section III.

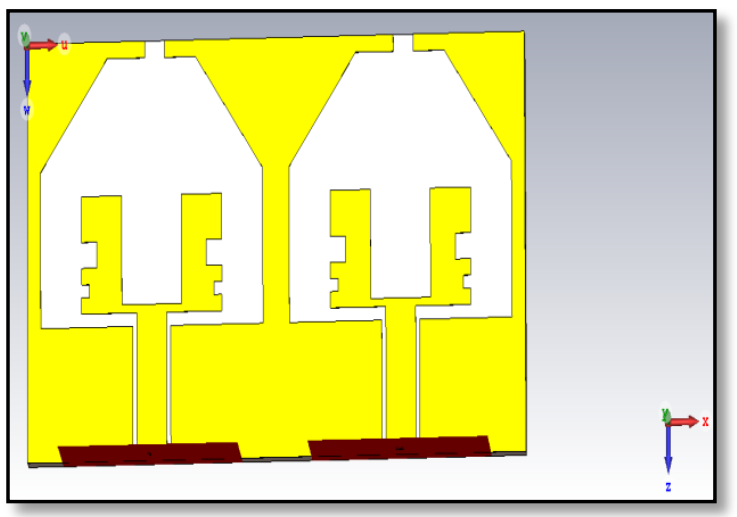

Fig 4: $1 \mathrm{X} 2$ proposed array antenna

\subsection{X4 Array Antenna Implementation}

Here we implement $1 \mathrm{X} 4$ Array Antenna of size is $100 \mathrm{X} 25 \mathrm{X} 1.6 \mathrm{~mm}^{2}$.FR-4 with $\mathrm{Er}=4.3, \delta=0.025$ is used as antenna substrate shown in fig 5 and results are disused in section III.

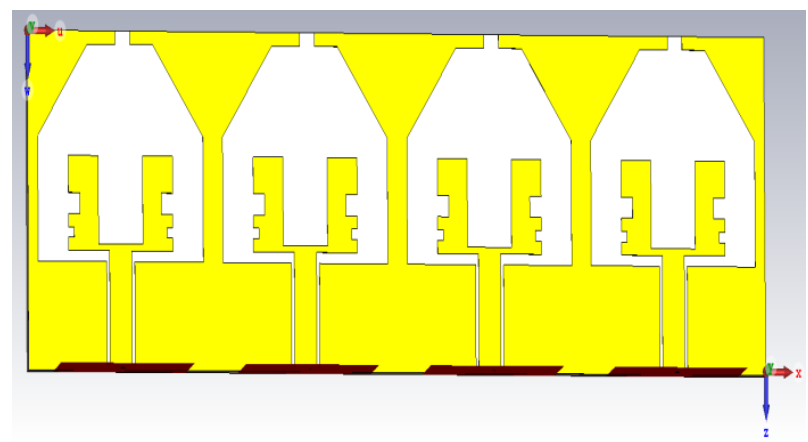

Fig.5: 1X4 proposed antenna Array 


\subsection{Design Procedure for Proposed for Proposed Power Divider}

Fig. 6 demonstrates the schematic diagram of the conventional two-section Wilkinson power divider with adjusted port. For better coupling and impedance coordinating, as can be found in Fig. 4. The proposed WB power divider is simulated with electromagnetic solvers in view of MOM. The sizes of a power splitter with moderately great execution were resolved. The insulation resistance $\mathrm{R}=100 \Omega$. Fundamentally, here the structure depends on the variable band microstrip technique. What's more, to enhance the large bandwidth utilizing the variable-width innovation appeared in Fig.7, the width and length of the substrate is appeared. The power divider WB has simulated and measured the substrate FR-4 with a dielectric constant $\varepsilon r=4.4$ and a thickness of $1.6 \mathrm{~mm}$ and the insulating resistance $\mathrm{R}=100 \Omega$ has been utilized. And every one of the measurements are appeared in TABLE3.

Table 3: Dimensions of the Proposed $1 \mathrm{X} 2$ Power Divider

\begin{tabular}{|c|c|c|}
\hline S.No & Dimension & $\begin{array}{c}\text { Calculated Value } \\
\text { (Millimetres) }\end{array}$ \\
\hline 1 & $\mathrm{~L}_{1}$ & 4.3 \\
\hline 2 & $\mathrm{~L}_{2}$ & 6 \\
\hline 3 & $\mathrm{~L}_{3}$ & 4.5 \\
\hline 4 & $\mathrm{~L}_{4}$ & 1.7 \\
\hline 5 & $\mathrm{~L}_{5}$ & 11.42 \\
\hline 6 & $\mathrm{~L}_{6}$ & 10.3 \\
\hline 7 & $\mathrm{~W}$ & 1 \\
\hline 8 & $\mathrm{~g}_{1}$ & 1 \\
\hline 9 & $\mathrm{~g}_{2}$ & 0.7 \\
\hline 10 & $\mathrm{~g}_{3}$ & 0.2 \\
\hline
\end{tabular}

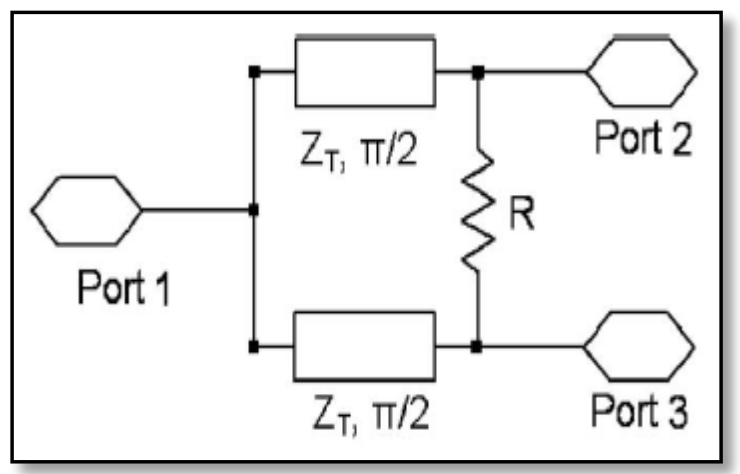

Fig. 6:Schematic diagram of $1 \mathrm{X} 2$ Wilkinson power divider

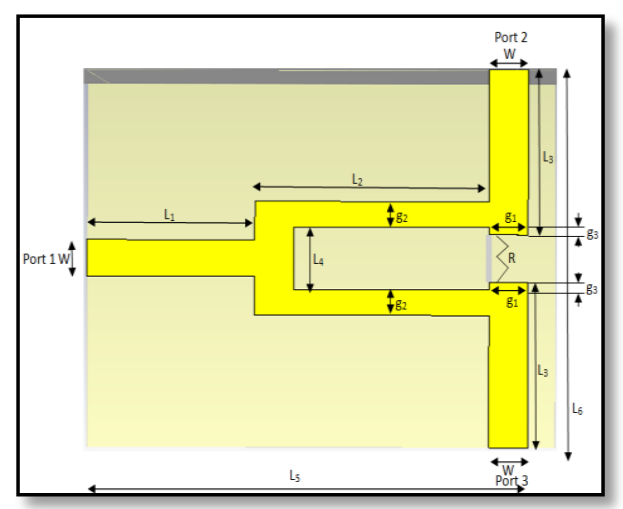

Fig.7:Layout of Proposed 1X2 WB Power Divider (Dimension is 11.42 $\mathrm{mm} \times 10.3 \mathrm{~mm}$ )

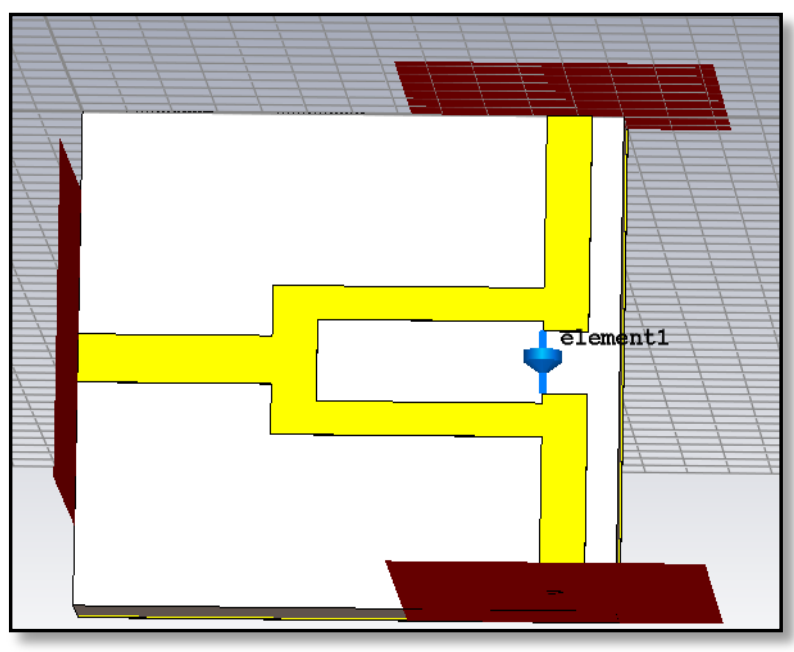

Fig 8: Basic 1X2 Wilkinson power divider

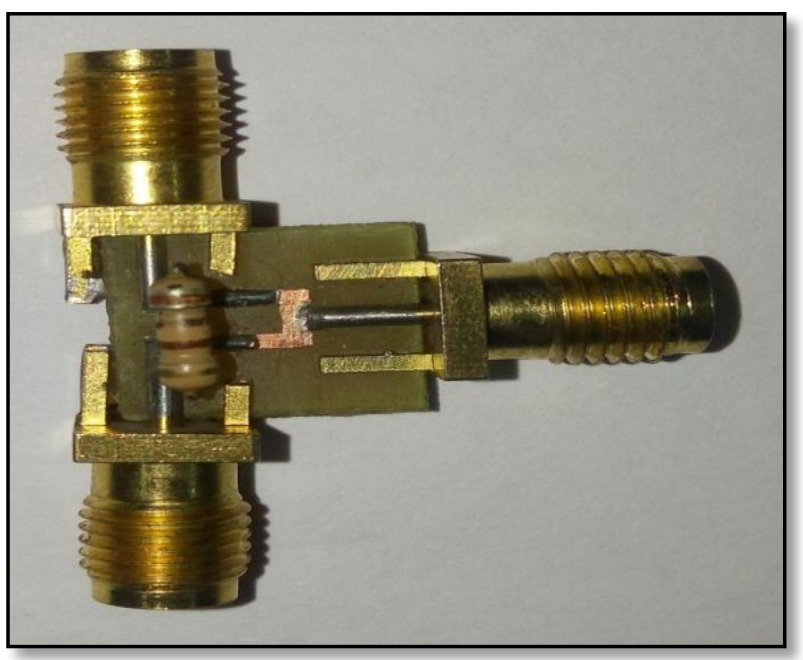

Fig 9: Fabricated Structure of Proposed WB Power

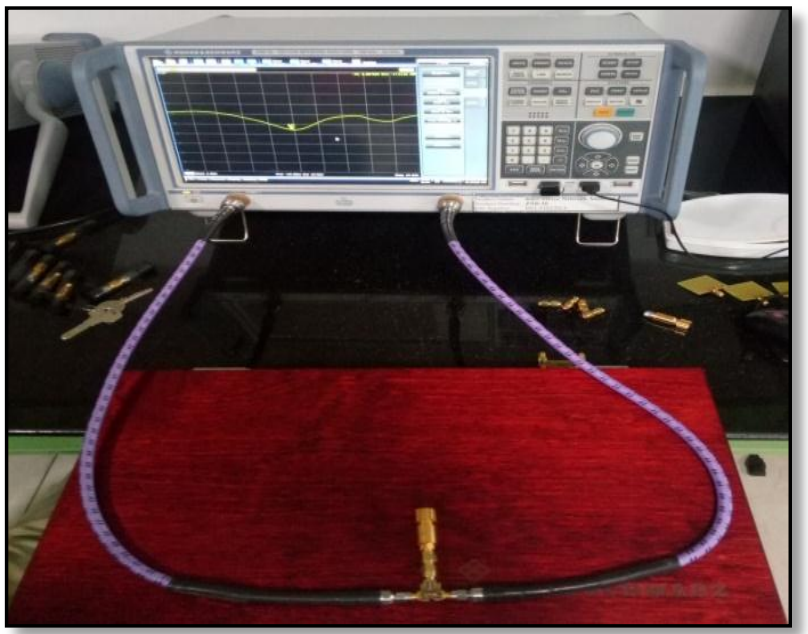

Fig 10: Testing arrangement of proposed $1 \mathrm{X} 2$ power Divider on FR4 material

\subsection{Structure of Proposed Four-Way Wilkinson Power Divider}

The implementation of $1 \mathrm{X} 4$ power is also same as $1 \mathrm{X} 2$ power divider only difference is arms are attached at the port 2 and port3 of the $1 \mathrm{X} 2$ proposed power divider then $1 \mathrm{X} 4$ proposed power divider is established in fig8 and Dimensions are shown in table4 and results are discussed in section III 


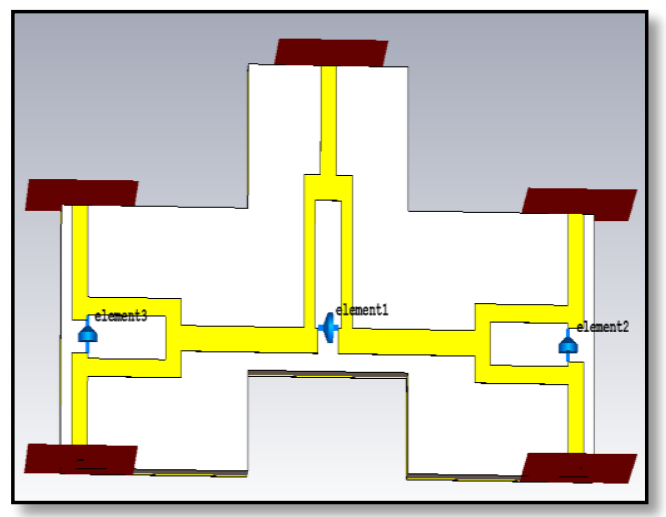

Fig. 11: Basic 1X4 Wilkinson power divider

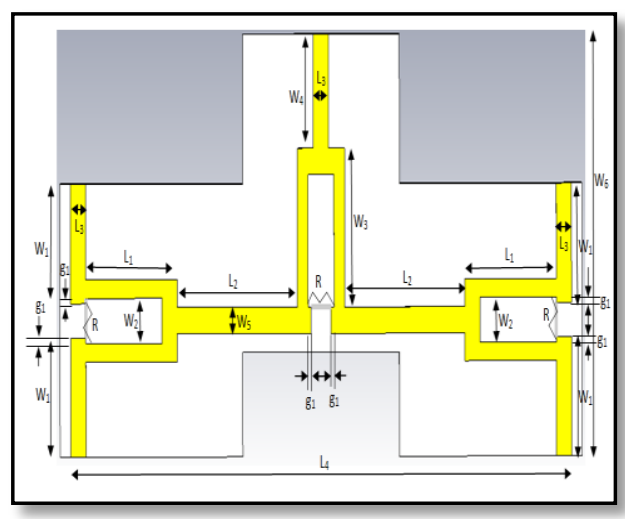

Fig. 12:Layout of Proposed 1X4 WB Power Divider (Dimension 32.9mm $\times 22.55 \mathrm{~mm}$ )

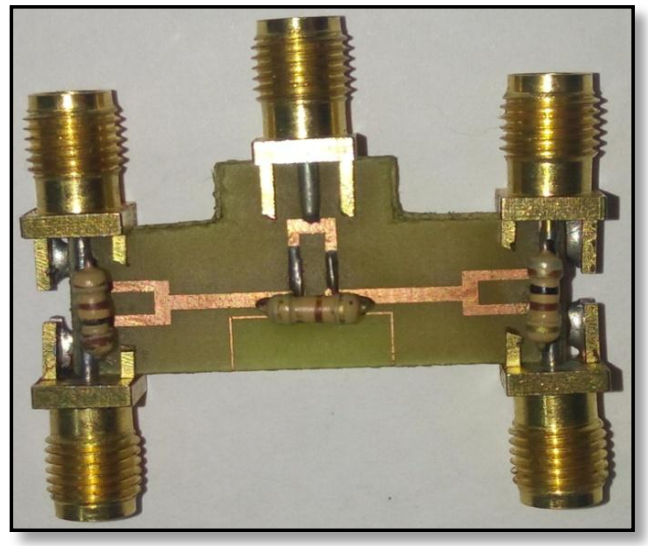

Fig.13: Fabricated Structure of Proposed 1X4 WBPowerDivider (Dimension is $32.9 \mathrm{~mm} \times 22.55 \mathrm{~mm}$

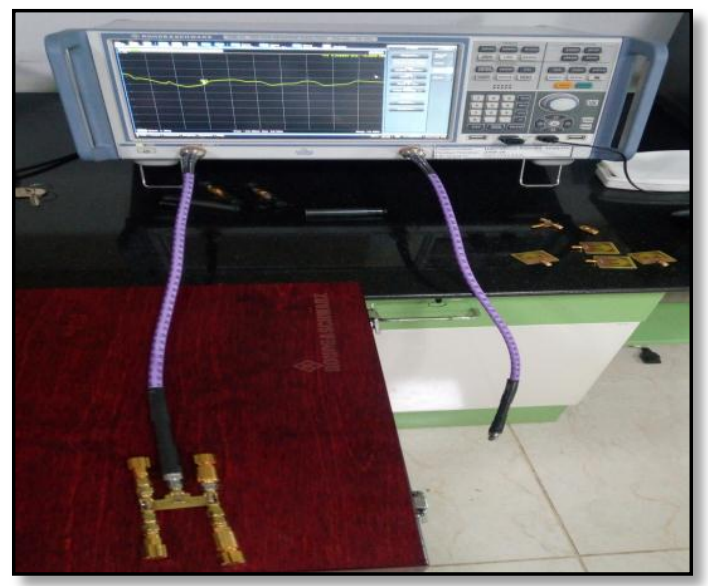

Fig 14: Testing arrangement of proposed $1 \mathrm{X} 4$ powerDivider on FR4 Material
Table 4: Dimensions of the Proposed 1X4 Power Divider

\begin{tabular}{|c|c|c|}
\hline S.No & Dimension & $\begin{array}{c}\text { Calculated Value } \\
\text { (Millimetres) }\end{array}$ \\
\hline 1 & $\mathrm{~W}_{1}$ & 4.5 \\
\hline 2 & $\mathrm{~W}_{2}$ & 1.7 \\
\hline 3 & $\mathrm{~W}_{3}$ & 6 \\
\hline 4 & $\mathrm{~W}_{4}$ & 4.3 \\
\hline 5 & $\mathrm{~W}_{5}$ & 1 \\
\hline 6 & $\mathrm{~W}_{6}$ & 22.55 \\
\hline 7 & $\mathrm{~L}_{1}$ & 6 \\
\hline 8 & $\mathrm{~L}_{2}$ & 7.9 \\
\hline 9 & $\mathrm{~L}_{3}$ & 1 \\
\hline 10 & $\mathrm{~L}_{4}$ & 32.9 \\
\hline 11 & $\mathrm{~g}_{1}$ & 0.2 \\
\hline 12 & $\mathrm{R}$ & $100 \Omega$ \\
\hline
\end{tabular}

\subsection{Array Implementation Using 1X2 Power Divider}

Here attaching two U-slot antennas to the power divider port2 and power divider port3 for equal power division whenever we are adding the antenna to the power divider then the parameter like Directivity, Gain, Radiation pattern and Return loss results are fall down so we move for optimization for better results and results are disused in section III.

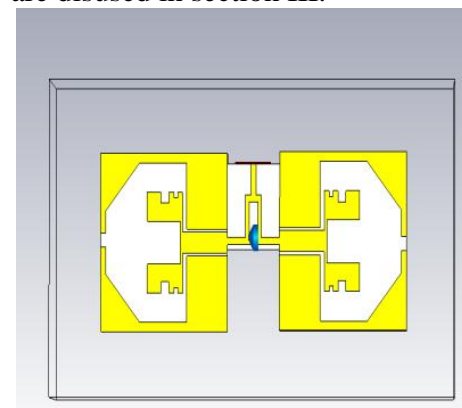

Fig. 15: $1 \mathrm{X} 2$ Antenna Array using power divider

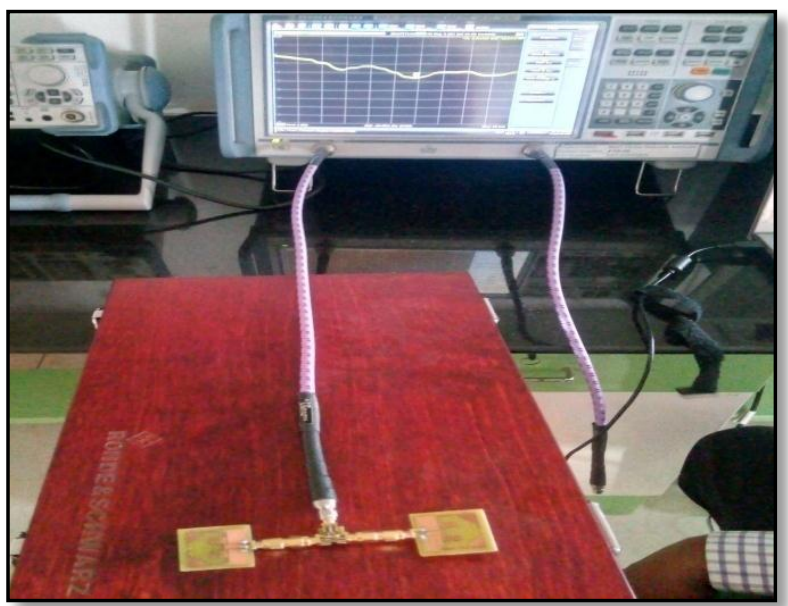

Fig. 16:Testing arrangement of proposed $1 \mathrm{X} 2$ Antenna Array using power divider

\subsection{Array Implementation Using 1X4 Power Divider}

Here we Consider first single power divider port 1 is input port at port 2 and port 3 we connecting another power dividers its look like a shape of inverted $\mathrm{T}$ shape at left side power divider at port 2 we connecting basic U-slot antenna the same way we connecting at port3, port4, port5 finally it forms as $1 \mathrm{X} 4$ antenna array using power divider shown in fig and results are disused in section III 


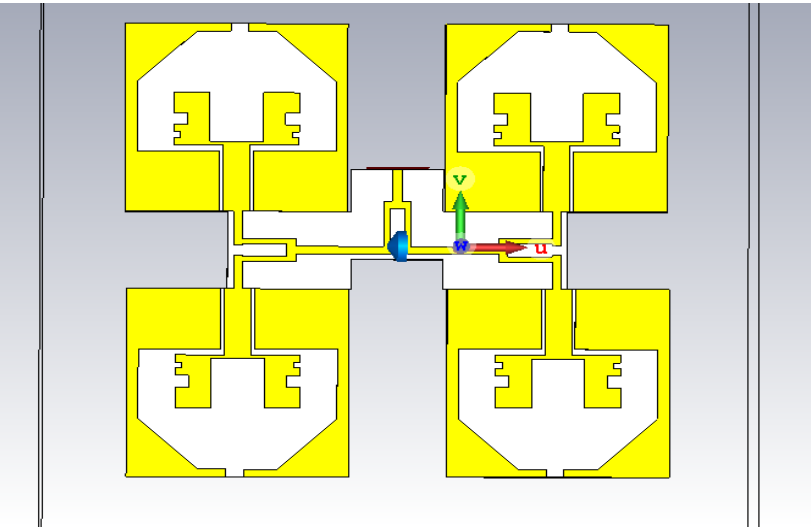

Fig. 17:1X4 antenna Array using power divider

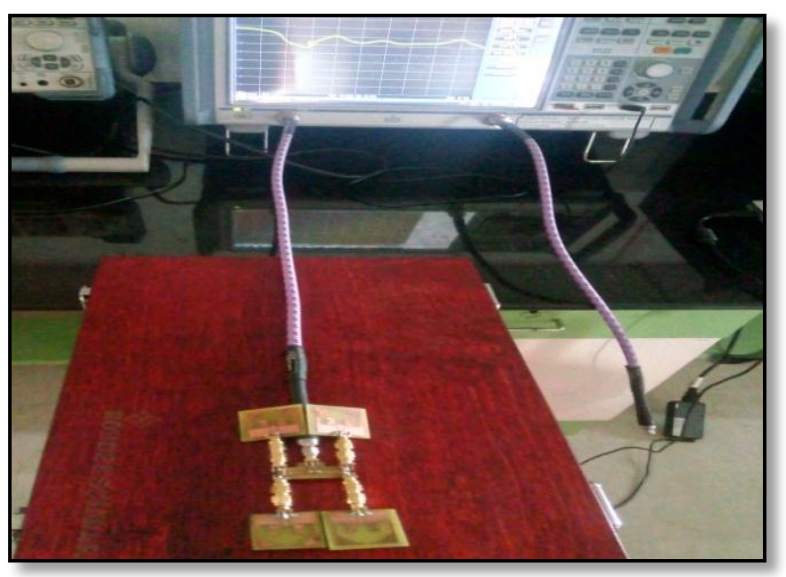

Fig. 18:Testing arrangement of proposed $1 \mathrm{X} 4$ Antenna Array using power divider

\subsection{Fire Fly, Cuckoo, Spring Cuckoo Optimizations}

\subsubsection{Firefly Optimization on UWBArray Antenna}

Many applications took the firefly algorithm as a standard as it is attracted with its features. Some of the demonstrations by Horng et.al confirmed that fire fly-based algorithm uses least computation time for digital image compression. This firefly algorithm was also utilized by Banati and Bajajfor the purpose of feature selection and proved that this algorithm gave a better and a consistent performance in the case of time and optimality compared to the other algorithms.

The highly non-linear and all the multimodal design problems can be efficiently solved by the firefly algorithm which was confirmed by Gandomi et.al Azad. The Firefly algorithm was proved to outperform the artificial bee colony which is $\mathrm{ABC}$ algorithm when it was applied in the antenna design optimization. Futher more it was also proves that this algorithm out performed the PSO algorithm and also obtained the best global results.

The discrete version of the Firefly Algorithm was proved to efficiently solve the NP-hard scheduling problems. The detailed analysis gave a conclusion that the firefly algorithm was efficient compared to a wide range of test problems. All the scheduling and the travelling salesman problems can be easily solve in a promising way using the Firefly algorithm.

\section{FIREFLY ALGORITHM}

Begin

1) Objective function: $f(x), x=(x 1, x 2 \ldots \ldots, x n)$;

2) Generate an initial population of fireflies $\mathrm{xi}=1,2,3 \ldots \ldots . \mathrm{n}$;

3) Formulate light intensity I so that it is associated with $f(x)$ $\mathrm{f}(\mathrm{x})$ )

(for example, for maximization problems, or simply I =

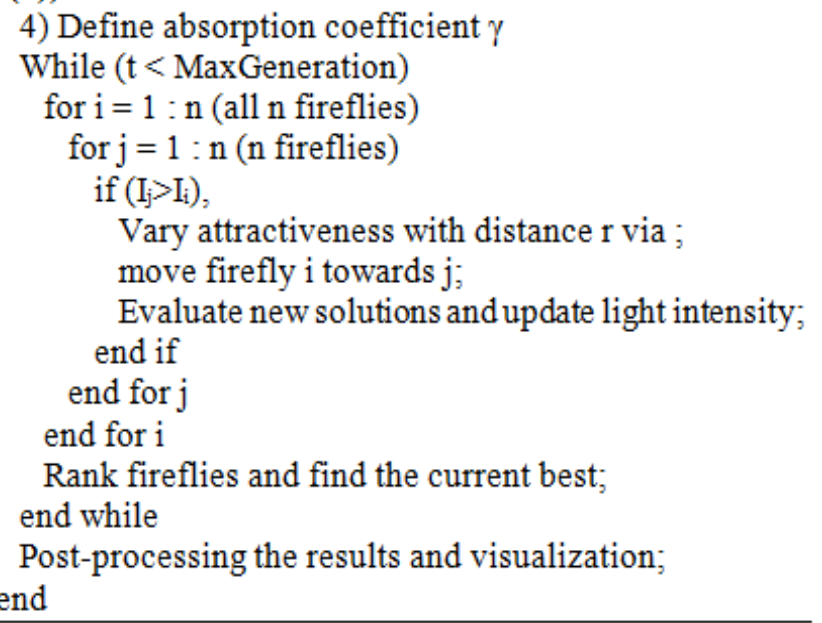

\subsubsection{Cuckoo Search Optimization on UWBArray Antenna}

The description of the new Cuckoo search can be given easily with the three ideal rules:

1) A nest is randomly chosen and the by the cuckoo for dumping its egg laid one at a time.

2) The high quality eggs in the best nests will be carried out to the next generations.

3) The egg that is laid by the cuckoo is found out by the host bird with a probability pa $2[0,1]$ as the number of available host nests are fixed.

According to the above case the hosting bird can either throw the egg far away or construct a new nest. Further more simplifying the last assumption by the approximation of the fraction of the nests can be replaced by the new nests which are randomly chosen. For a maximization problem, the fitness of a solution will be proportional to the value of the objective function. All the other forms of the fitness function are also developed in a similar way to the existing fitness function in all the genetic algorithms. For easy understanding the representations like each of the eggs in those nests will represent a solution and the good cuckoo egg will definitely represent a new solution to the problem. Finally, the aim is to get a new solution to replace the old not so good solutions in the nests. As this algorithm can be extended by a more complicated case as the nests that are present has more number of eggs representing a different set of solutions. Here the most simplest approach where the assumption is that the nest has only single super egg. 


\section{ALGORITHM FOR CUCKOO SEARCH}

begin

Objective function $f(x), x=(x 1, \ldots, x d) T$

Generate initial population of $n$ host nests xi $(i=1,2, \ldots, n)$

while ( $t<$ MaxGeneration) or (stop criterion)

Get a cuckoo randomly by L'evy flights evaluate its quality/fitness Fi

Choose a nest among $n(s a y, j)$ randomly

if $(\mathbf{F i}>\mathbf{F j})$,

replace $\mathrm{j}$ by the new solution

end

A fraction (pa) of worse nests are abandoned and new ones are built;

Keep the best solutions (or nests with quality solutions); Rank the solutions and find the current best end while

Postprocess results and visualization end

\subsubsection{Spring Search Optimization on UWB Array Antenna}

The objective of this work is to propose a new hybrid algorithm of search of cuckoo with a Nelder-Mead method to overcome the slow convergence of the standard cuckoo search. The NelderMead method accelerates the search of the proposed algorithm and increases the convergence of the proposed algorithm. The proposed algorithm is called hybrid cuckoo search with NelderMead (HCSNM). In the HCSNM algorithm, we combine the cuckoo search with a Nelder Mead method to accelerate the search and avoid running the algorithm with more iterations without any improvement.

The main difference between our proposed algorithm and the other hybrid search algorithms Cuckoo and Nelder-Mead is the way to apply the Nelder-Mead method. The authors in Chang et al., Jovanovic et al. they have invoked the Nelder Mead method in the cuckoo search algorithm instead of the flight operator Levy. The drawback of this idea is the calculation time because the NM method is called in each iteration in the Cuckoo search algorithm. However, in our proposed algorithm we execute the standard CS algorithm for some iterations, then we pass the best solution found to the Nelder-Mead method to start with a good solution that helps the NM method to obtain the global minimum of the functions in a reasonable time.

\section{SPRING CUCKOO SEARCH ALGORITHM}

1: Set the initial value of the host nest size $n$, probability $p a \in[0,1]$ and maximum number of iterations Maxitr.

2 : Set $t:=0$. \{Counter initialization\}

3: for $(i=1: i \leq n)$ do

4: Generate initial population of $n$ host $x(t)$ $i$. $\{n$ is the population size $\}$

5: Evaluate the fitness function $f(x(t) i)$.

6: end for

7: repeat

8: Randomly generate a new solution (Cuckoo) $x(t+1)$ $i$ by L'evy flight

9: Evaluate the fitness function of a solution $x(t+1)$ $i f(x(t+1) i)$

10: Randomly choose a nest $x j$ among $n$ solutions.

11 : if $(f(x(t+1) i)>f(x(t) j))$ then

12: Replace the solution $x j$ with the solution $x(t+1) i$

13: end if

14: Abandon a fraction pa of worse nests.

15: Build new nests at new locations using L'evy flight a fraction $p a$ of worse nests

16: Keep the best solutions (nests with quality solutions)

17: Rank the solutions and find the current best solution

18: Set $t=t+1$.

19: until ( $t \geq$ Maxitr). \{Termination criteria are satisfied

20: Produce the best solution.

\section{Results and Discussions}

This section presents all results of U-Slot antenna, Array antenna, power divider and optimization values all are discussed. First we discus return loss parameter of U-Slot antenna shown if Fig.11(a), return loss value is $-57.02 \mathrm{~dB}$ at a frequency of $8.23 \mathrm{GHz}$, VSWR shown in fig.11(b) the value is 1.2,Directivity shown in fig.11(c) , the value is $4.64 \mathrm{dBi}$, gain shown in fig. $11(\mathrm{~d})$ the value is 3.96 , and finally radiation pattern is shown in fig.11(e). All these values are simulated values. Now we discuss measured values for the $\mathrm{u}$ slot antenna Return loss value is -50.0124 shown in fig.11 (f), VSWRis 1.32 shown in fig. $11(\mathrm{~g})$

Now we Discus 1X2 array antenna results in fig.12 (a)shows Return loss of the $1 \mathrm{X} 2$ array antenna the value is $-37.5233 \mathrm{~dB}$, at a frequency of $8.33 \mathrm{GHz}$, VSWR shown in fig.12(a) value is 1.32 , Directivity shown in fig.12(c), Value is $5.21 \mathrm{dBi}$, Gain is shown in fig. $12(\mathrm{~d})$ the value is $4.75 \mathrm{~dB}$, finally radiation pattern is shown in fig.12(e). Next we discus 1X4 array antenna results fig.13(a) shows Return loss of the $1 \mathrm{X} 4$ array antenna the value is $-59.81 \mathrm{~dB}$, VSWR shown in fig.13(b) value is 1.02 , Directivity shown in fig.13(c) Value is $5.61 \mathrm{dBi}$, Gain is shown in fig.13(d) the value is 4.75 , finally radiation pattern is shown in fig. $13(\mathrm{e})$

In Fig. 11(a) $\mathrm{S}_{11}$ parameter of $1 \mathrm{X} 2$ power divider is presented. Return loss of the $1 \mathrm{X} 2$ power divider achieved $-24.668 \mathrm{~dB}$ at 8.18 $\mathrm{GHz}$ wide band of $3 \mathrm{GHz}$ to $10.6 \mathrm{GHz}$ range is presented, and also $\mathrm{S}_{22}$ and $\mathrm{S}_{33}$ are presented at Fig. 11(b) and Fig. 11(c). Next discussion regarding insertion loss or transmission parameter of $1 \mathrm{X} 2$ power divider $S_{21} \& S_{31}$ are presented at figures of Fig. 12(a) to Fig. 12(b).

In Fig. 18(a) to Fig. 18(e) return loss parameters of $1 \mathrm{X} 4$ power divider is $-36.1725 \mathrm{~dB}$ at $8.896 \mathrm{GHz}$ band of $2 \mathrm{GHz}$ to $10 \mathrm{GHz}$ range is presented, for $\mathrm{S}_{22}-59.6248 \mathrm{~dB}$ at $9.946 \mathrm{GHz}$, for $\mathrm{S}_{33}$ $43.337 \mathrm{~dB}$ at $9.974 \mathrm{GHz}$, for $\mathrm{S}_{44}-36.4356 \mathrm{~dB}$ at $9.89 \mathrm{GHz}$, for $\mathrm{S}_{55}$ $37.91 \mathrm{~dB}$ at $10.058 \mathrm{GHz}$ are presented. In Fig. 19(a) to Fig. 19(d) Insertion loss of $1 \mathrm{X} 4$ power divider is presented. In Fig. 20(a) to Fig. 20(f) Isolation loss parameter is presented.The fabricated results of 1X2, 1X4 power divider of Return loss, Insertion loss, Isolation loss, VSWR are presented in fig.21 to fig.26

Finally optimization results of firefly, cuckoo search, spring cuckoo search results are shown in fig.29 (a) to fig.30 (d), that parameter are directivity, gain, radiation pattern and return loss parameters are presented. so here main purpose of using optimization is to enhance the antenna parameter. While we observing 1X2, 1X4 array antenna their antenna parameters are increases. While we attaching power divider to the $1 \mathrm{X} 2,1 \mathrm{X} 4$ array antenna results are fall down. To enhance the antenna parameter we go for optimization, using optimization the antenna parameters are enhanced shown in fig.29 (a) to fig.30 (d) and good agreement between simulated and measured results.

\section{3.a U-Slot Antenna Results}

\subsection{Return loss}




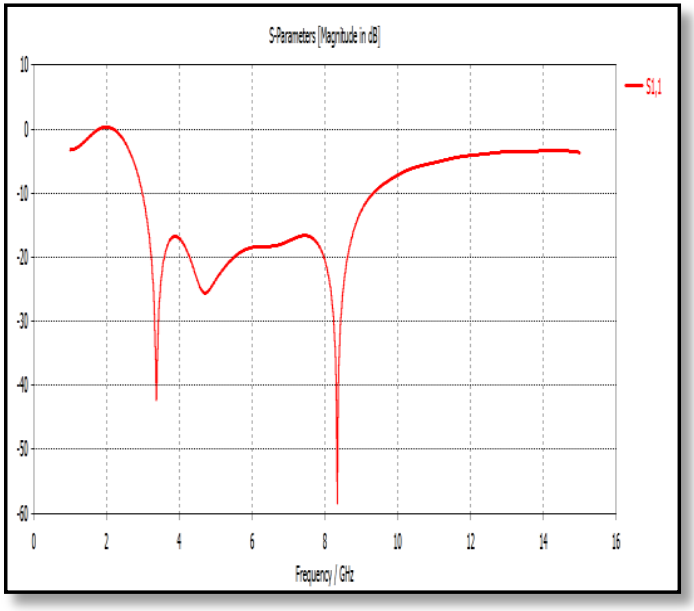

Fig.11 (a): Return loss parameter of U-Slot antenna

\subsection{VSWR}

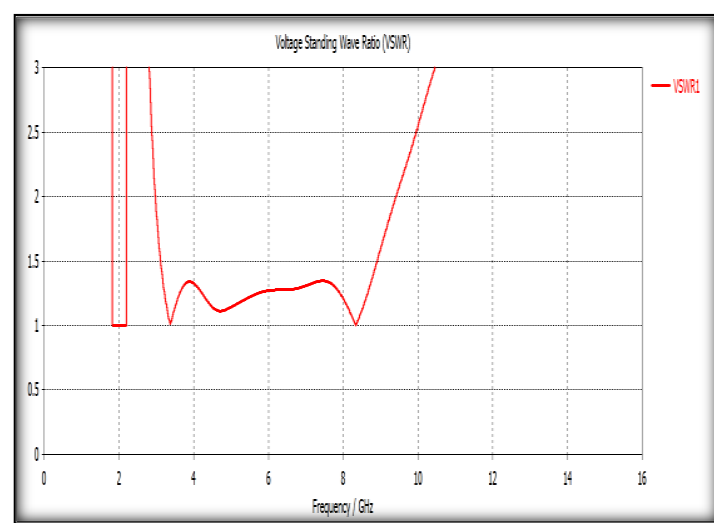

Fig.11 (b): VSWR parameter of U-Slot antenna

\subsection{Directivity}

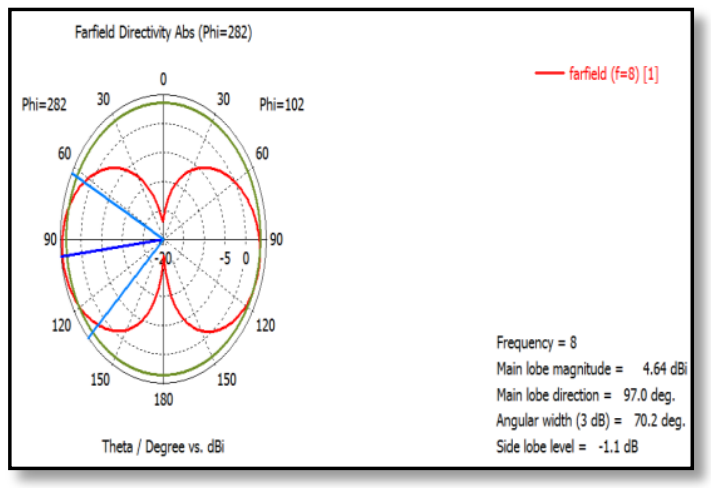

Fig.11(c): Directivity parameter of U-Slot antenna

\subsection{Gain}

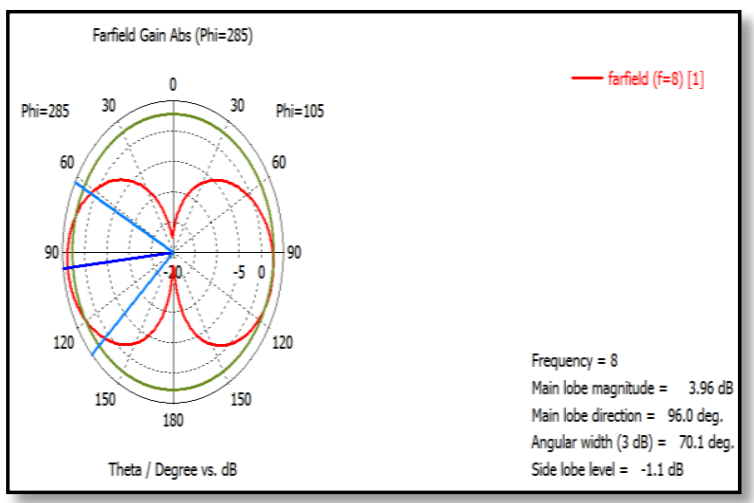

Fig.11 (d):Gain parameter of U-Slot antenna

\subsection{Radiation pattern}

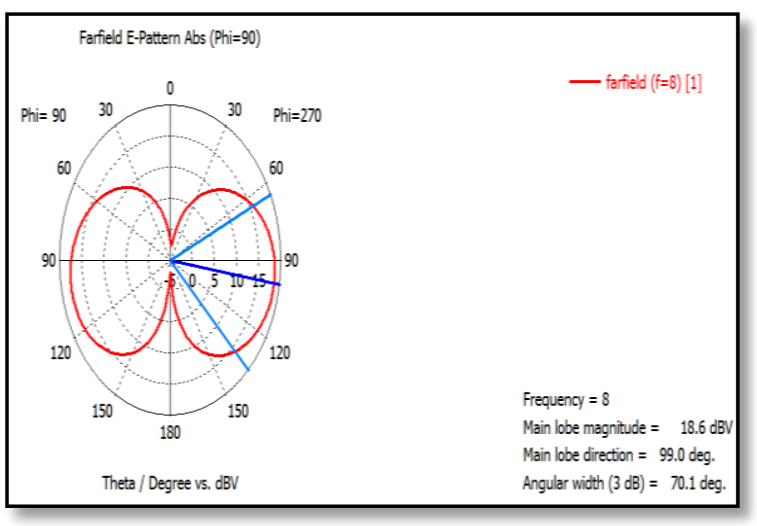

Fig.11 (e): Radiation parameter of U-Slot antenna

\section{3. b. Validation Results of U-Slot antenna}

\subsection{Return loss}

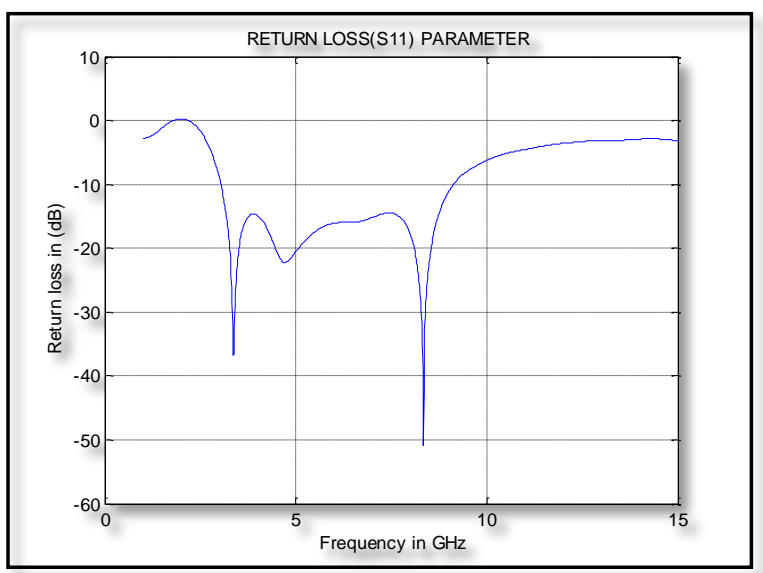

Fig.11 (f): Validation of Return loss parameter of proposed antenna

\subsection{VSWR}

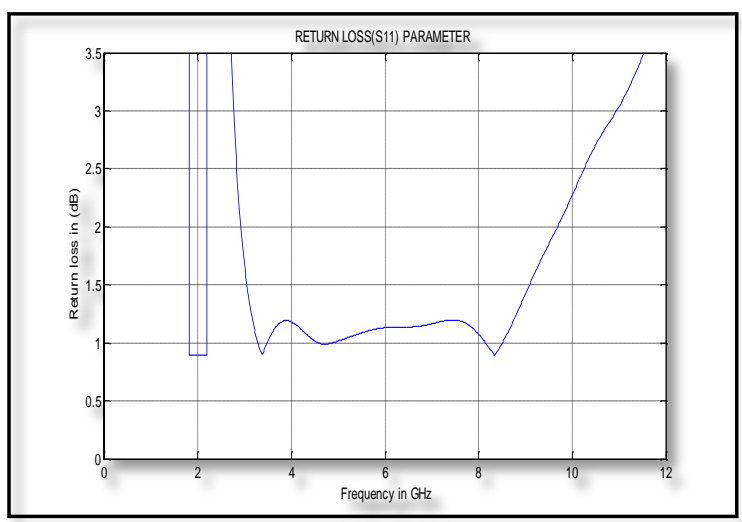

Fig.11 (g): Validation of VSWR parameter of proposed antenna

\section{3. c. 1X2 Array antenna Results}

\subsection{Return loss}




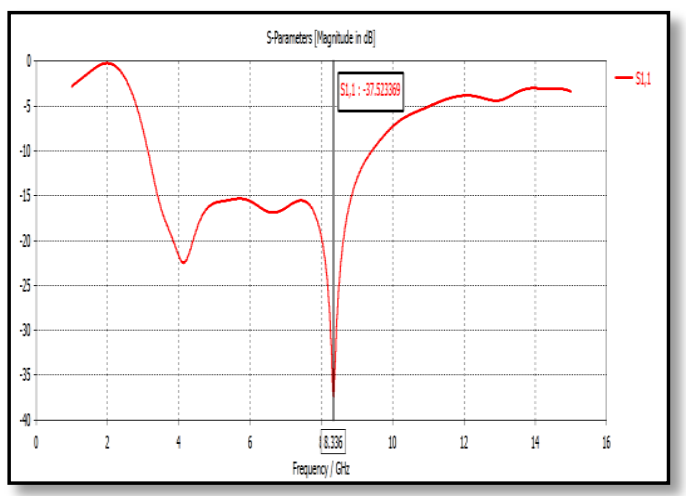

Fig.12 (a):.Return loss parameter of 1X2 proposed antenna

\subsection{VSWR}

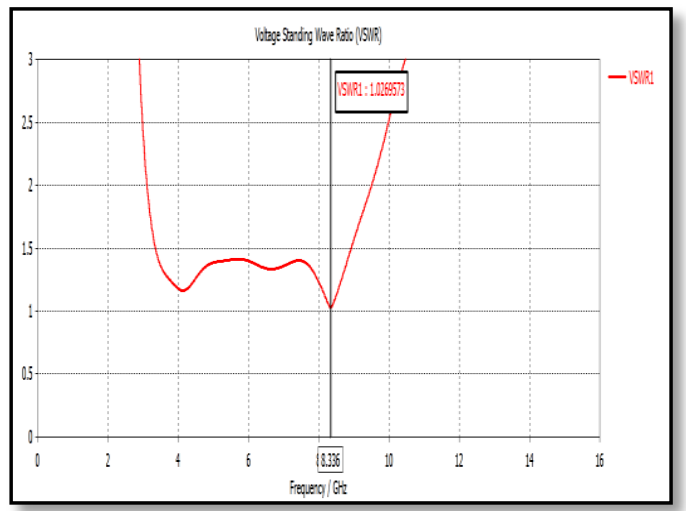

Fig.12 (b): VSWR parameter of 1X2 Proposed antenna

\subsection{Directivity}

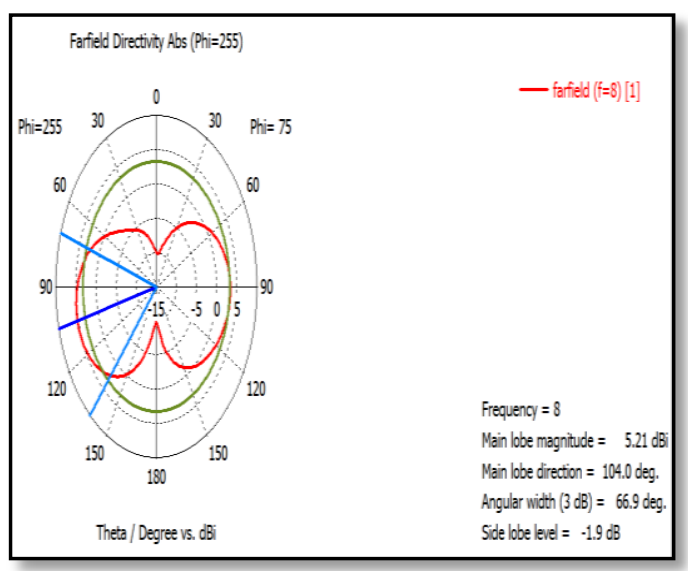

Fig.12(c): Directivity parameter of $1 \mathrm{X} 2$ proposed antenna

\subsection{Gain}

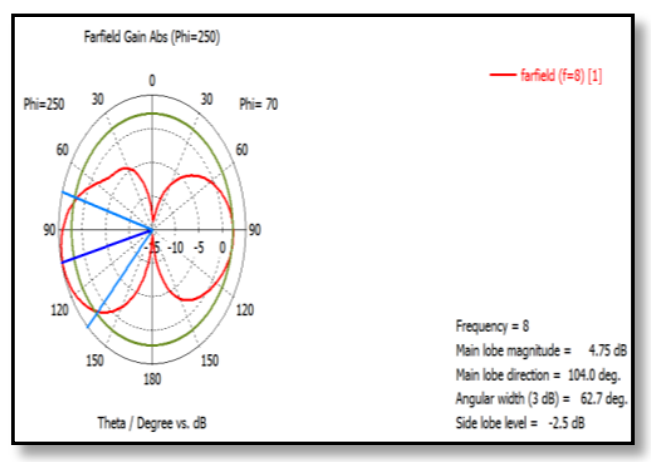

Fig.12 (d): Gain Parameter of 1X2 proposed antenna

\subsection{Radiation Pattern}

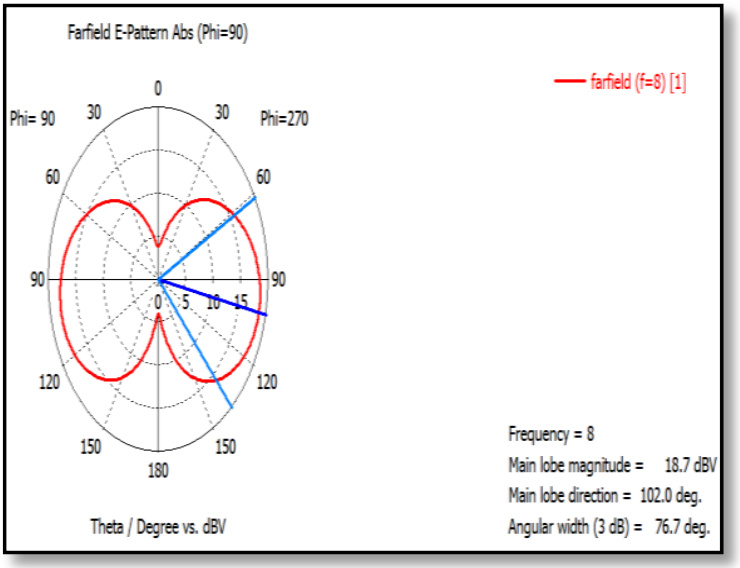

Fig.12 (e):Radiation Parameter of 1X2 proposed antenna

\section{3. d. 1X4 Array antenna Results}

\subsection{Return loss}

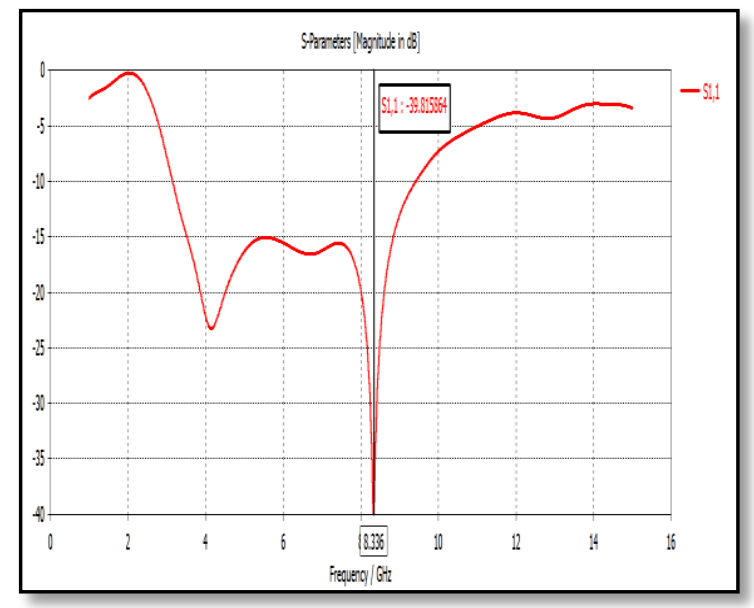

Fig.13 (a) Return loss parameter of 1X4 proposed antenna

\subsection{VSWR}

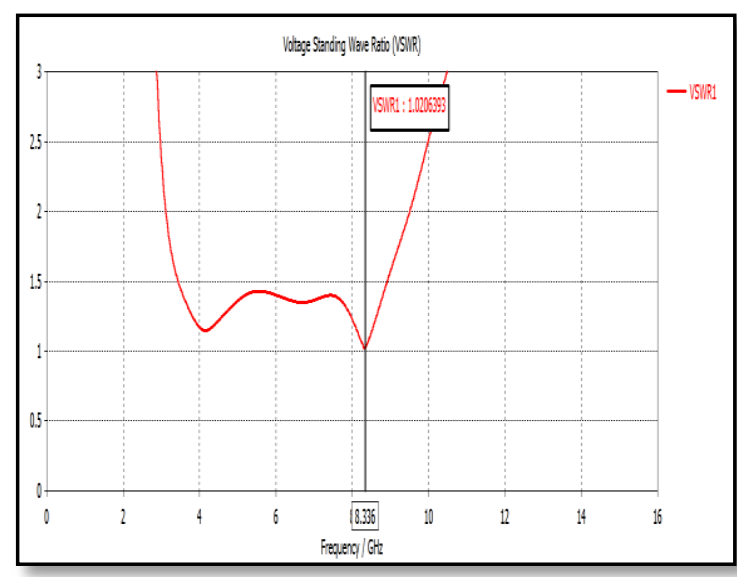

Fig.13 (b): VSWR parameter of 1X4 proposed antenna

\subsection{Directivity}




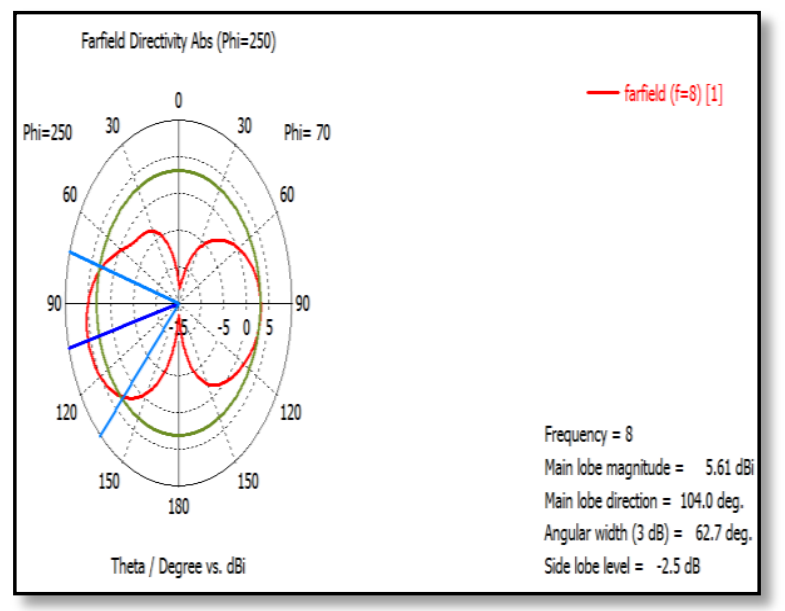

Fig.13(c): Directivity parameter of $1 \mathrm{X} 4$ proposed antenna

\subsection{Gain}

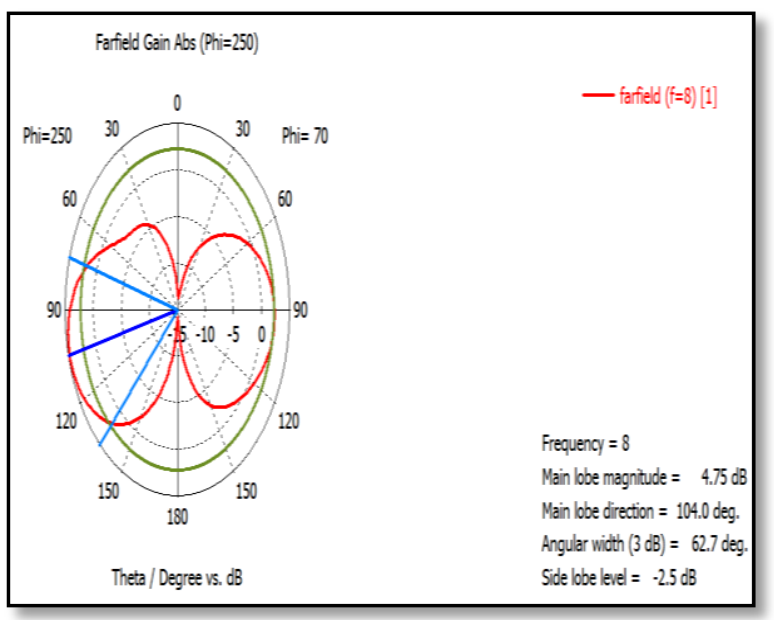

Fig.13 (d): Gain parameter of 1X4 proposed antenna

\subsection{Radiation Pattern}

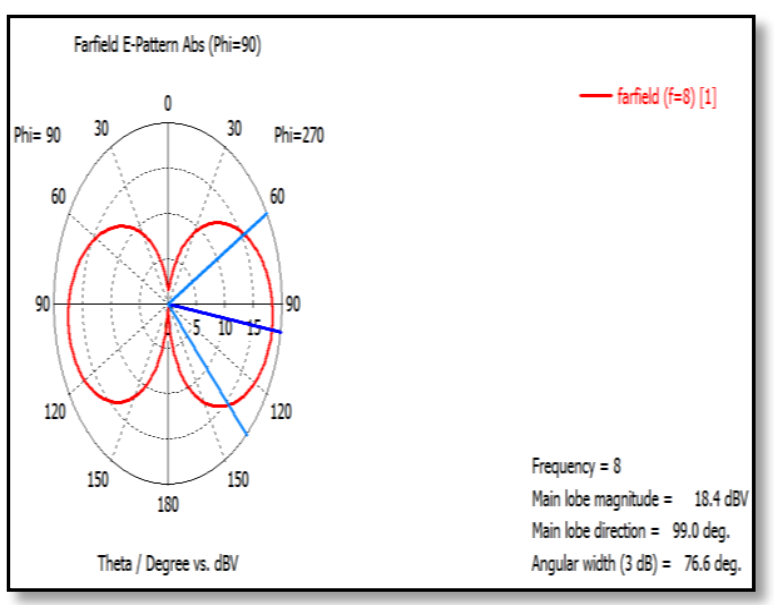

Fig.13 (e): Return loss parameter of 1X4 proposed antenna

\section{E. Basic 1X2 Wilkinson Power Divider Results}

\subsection{Return Loss of Proposed 1X2 Power Divider} $\mathbf{S}_{11}$

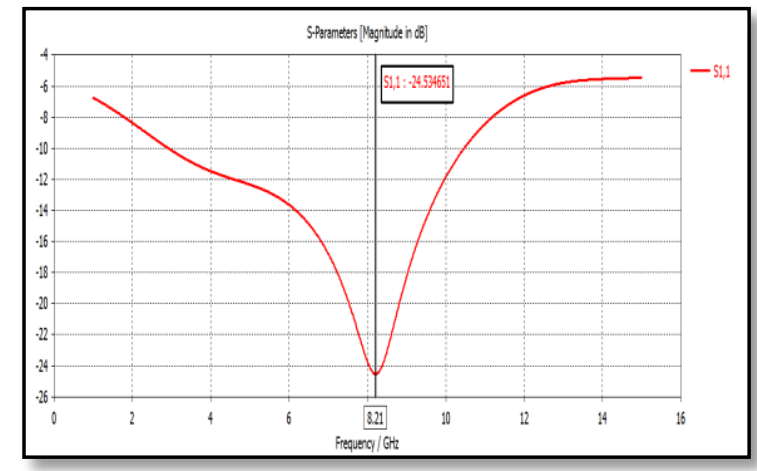

Fig. 14(a): Return loss $\left(S_{11}\right)$ parameter Performance of proposed $1 \mathrm{X} 2$ power divider

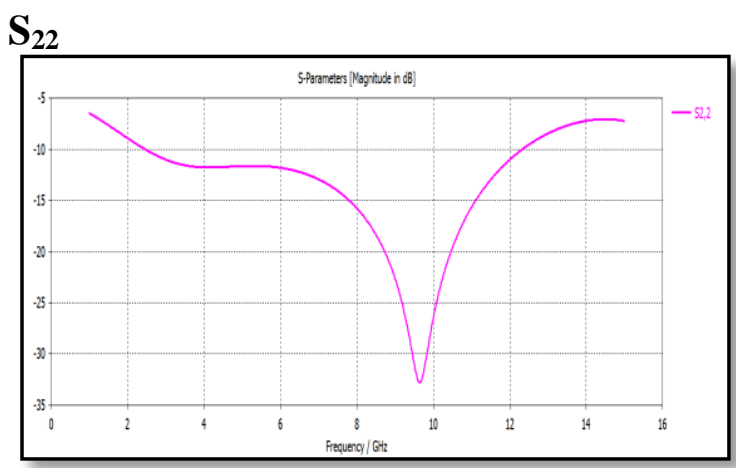

Fig. 14(b): Return loss $\left(S_{22}\right)$ parameter performance of proposed $1 \mathrm{X} 2$ power divider

$S_{33}$

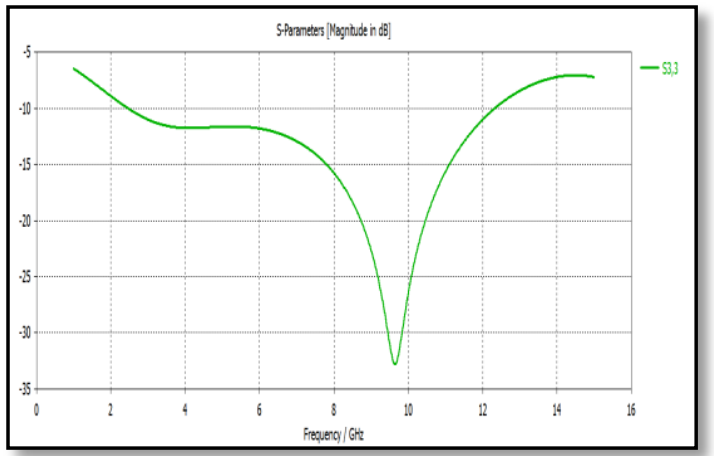

Fig. 14(c): Return loss $\left(S_{33}\right)$ parameter performance of proposed $1 \mathrm{X} 2$ power divider

\subsection{Insertion Loss or Transmission Parameter Of} proposed 1X2 power divider

$S_{21}$

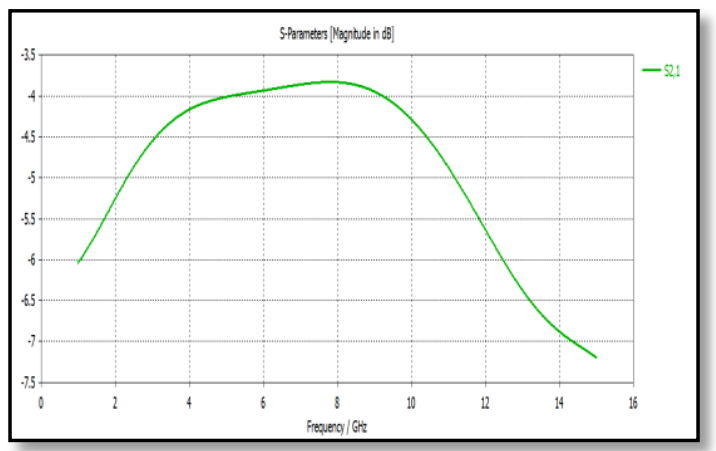

Fig 15(a): Insertion loss $\left(\mathrm{S}_{21}\right)$ parameter Performance of proposed $1 \mathrm{X} 2$ power divider 


\section{$\mathbf{S}_{31}$}

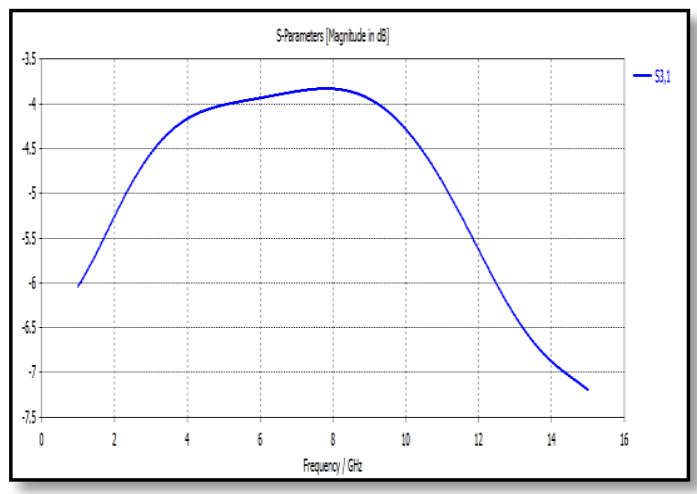

Fig 15(b): Insertion loss $\left(S_{31}\right)$ parameter Performance of proposed $1 \mathrm{X} 2$ power divider

\subsection{Isolation Loss of Proposed 1X2 Power Divider}

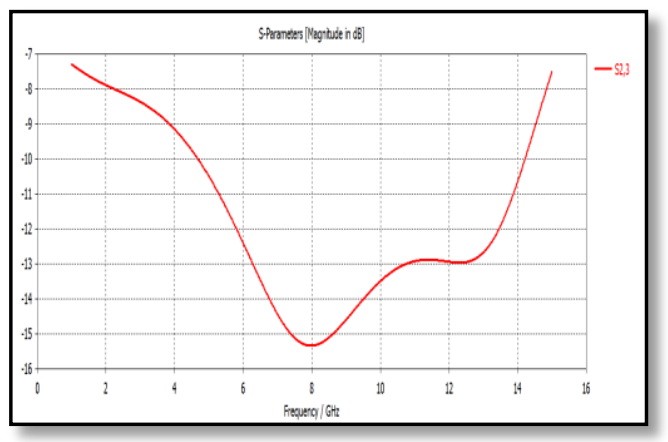

Fig. 16: Isolation loss (S23) performance of proposed $1 \mathrm{X} 2$ power divider

\subsection{VSWR of Proposed 1X2 Power Divider}

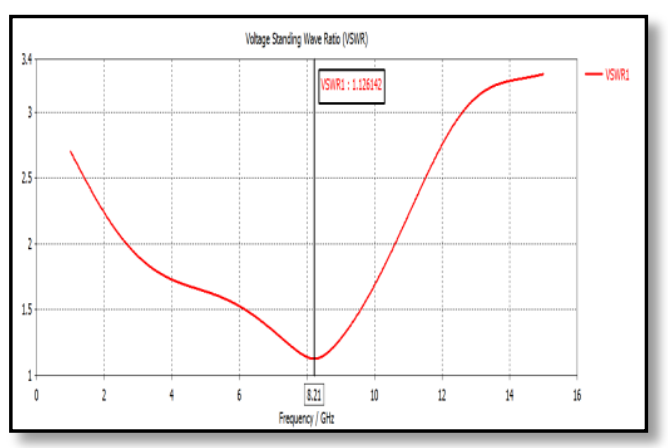

Fig. 17: VSWR performance of proposed $1 \mathrm{X} 2$ Power divider

\section{F. Basic 1X4 Wilkinson Power Divider Results}

\subsection{Return Loss of 1X4 Power Divider}

\section{$\mathrm{S}_{11}$}

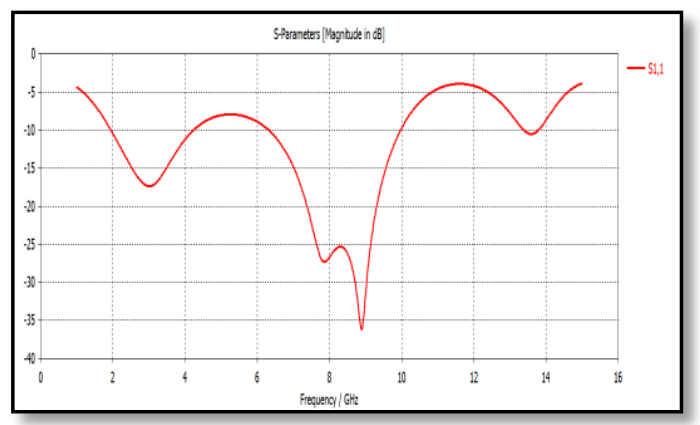

Fig. 18(a): Return loss $\left(S_{11}\right)$ parameter performance of proposed $1 \mathrm{X} 4$ power divide
S22

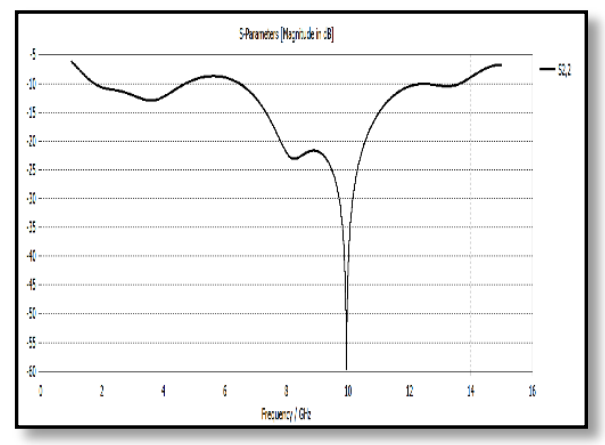

Fig. 18(b): Return loss $\left(\mathrm{S}_{22}\right)$ parameter Performance of proposed $1 \mathrm{X} 4$ power divider

$\mathbf{S}_{33}$

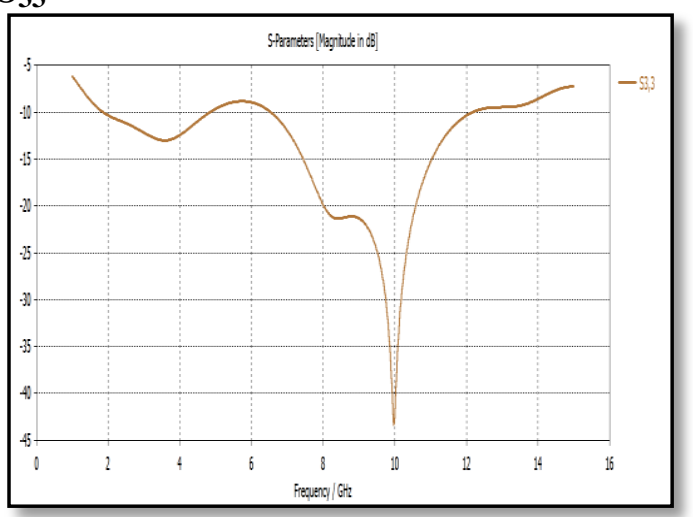

Fig. 18(c): Return loss $\left(\mathrm{S}_{33}\right)$ parameter performance of proposed $1 \mathrm{X} 4$ power divider

$\mathbf{S}_{44}$

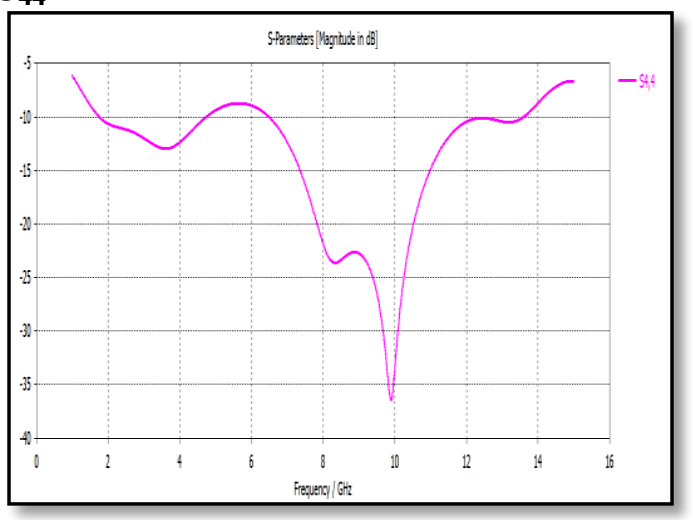

Fig. 18(d): Return loss $\left(S_{44}\right)$ parameter Performance of proposed $1 \mathrm{X} 4$ power divider

$\mathbf{S}_{55}$

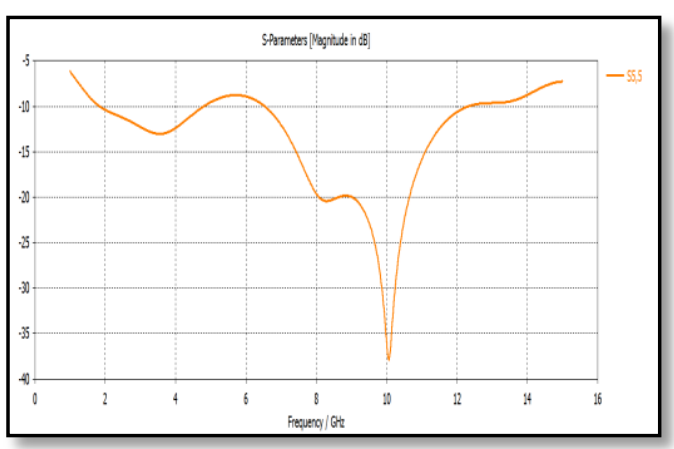

Fig. 18(e): Return loss $\left(S_{55}\right)$ parameter performance of Proposed $1 \mathrm{X} 4$ power divider 


\subsection{Insertion loss of proposed 1X4 power divider}

$\mathbf{S}_{21}$

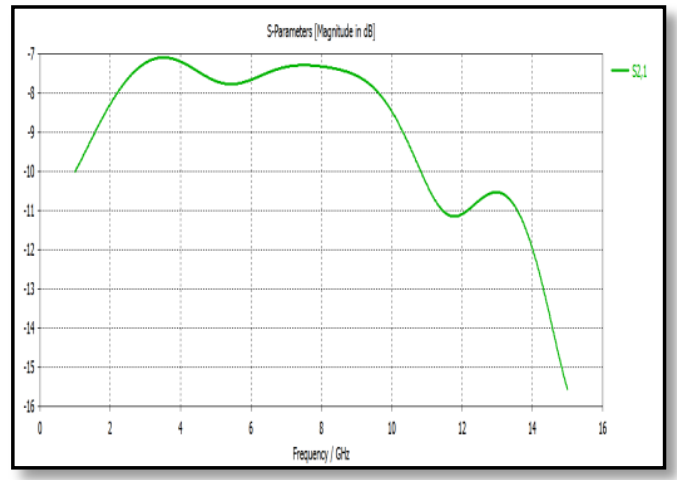

Fig. 19(a): Insertion loss (S21) parameter Performance of proposed $1 \mathrm{X} 4$ power divider

$\mathbf{S}_{31}$

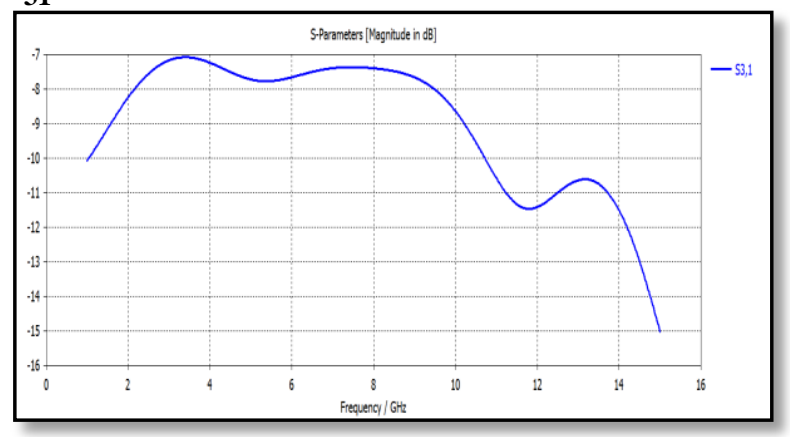

Fig. 19(b): Insertion loss (S31) parameterperformance of proposed $1 \mathrm{X} 4$ power divider

$\mathrm{S}_{41}$

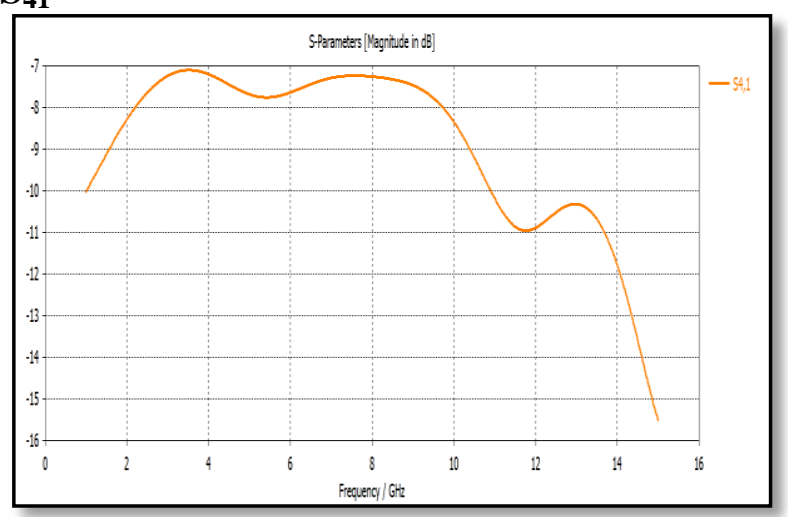

Fig. 19(c): Insertion loss (S41) parameterPerformance of Proposed $1 \mathrm{X} 4$ power divider

$\mathrm{S}_{51}$

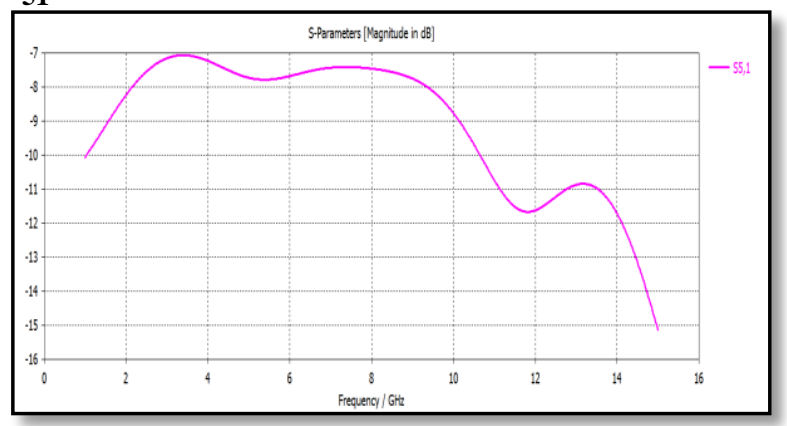

Fig. 19(d): Insertion loss (S51) parameter performance of proposed 1X4 power divider

\subsection{Isolation Loss of Proposed 1X4 Power Divider}

$\mathbf{S}_{23}$

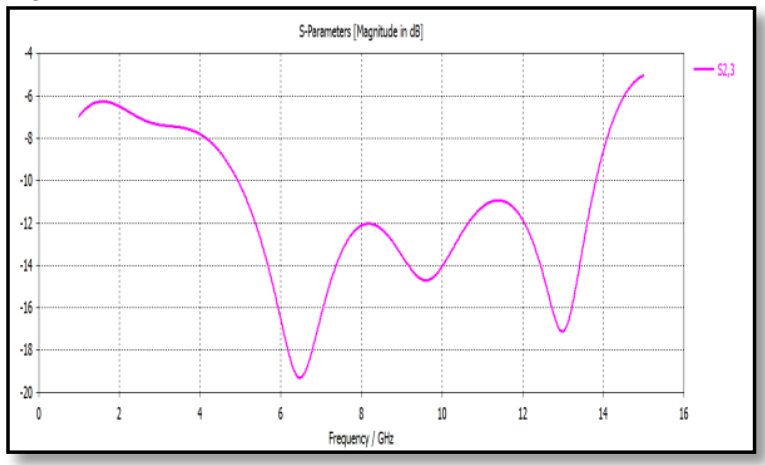

Fig. 20(a): Isolation loss (S23) parameter Performance of proposed $1 \mathrm{X} 4$ power divider

$\mathbf{S}_{24}$

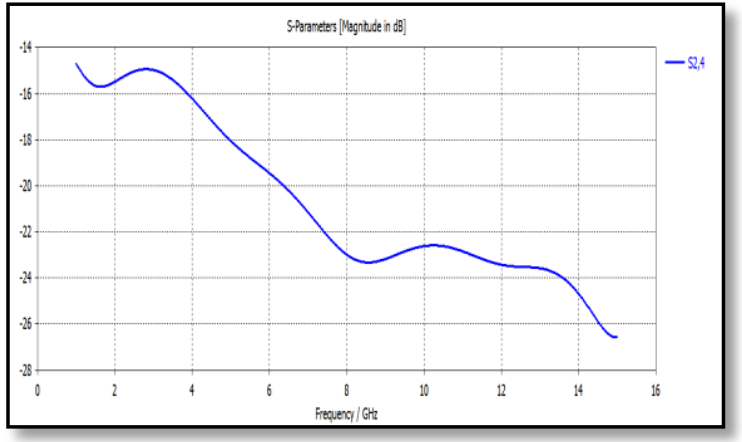

Fig. 20(b): Isolation loss (S24) parameter performance of proposed $1 \mathrm{X} 4$ power divider

$\mathbf{S}_{25}$

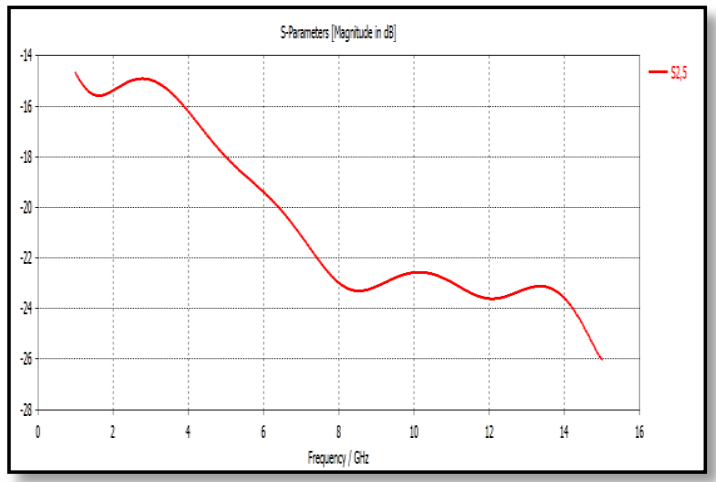

Fig 20(c): Isolation loss (S25) parameterPerformance of proposed $1 \mathrm{X} 4$ power divider

$\mathbf{S}_{34}$

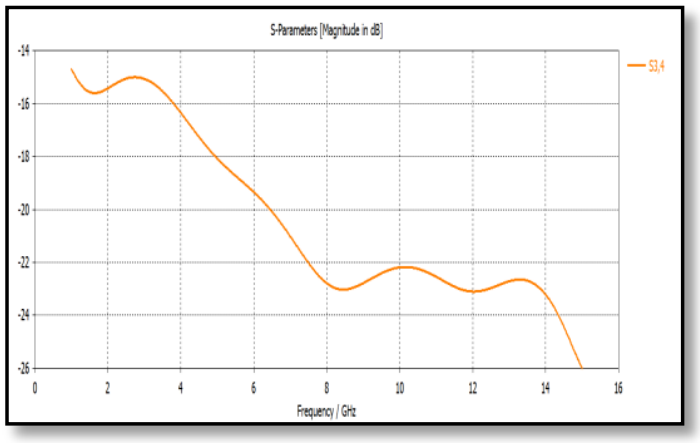

Fig. 20(d): Isolation loss (S34) parameter performance of proposed $1 \mathrm{X} 4$ power divider 


\section{$\mathbf{S}_{35}$}

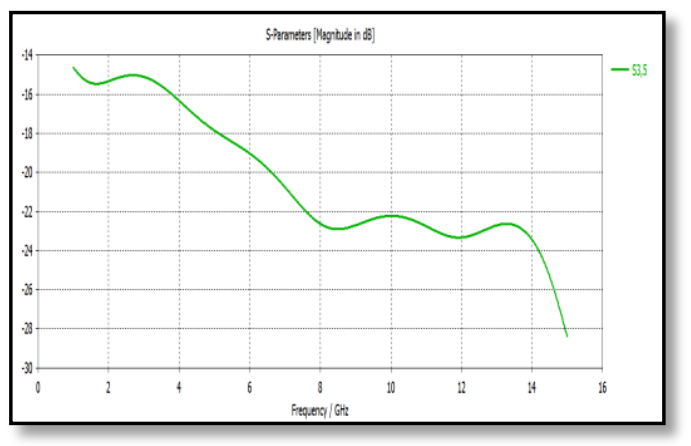

Fig. 20(e): Isolation loss (S35) parameter Performance of proposed $1 \mathrm{X} 4$ power divider

\section{$\mathbf{S}_{45}$}

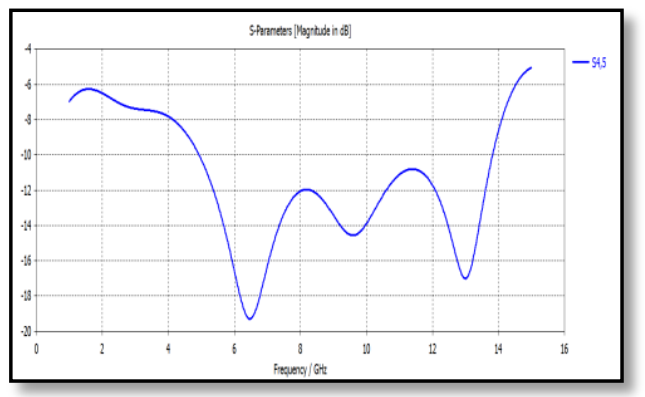

Fig. 20(f): Isolation loss (S45) parameterperformance of proposed $1 \mathrm{X} 4$ power divider

3. G. Validation of Proposed 1X2 Power Divider Parameters

\subsection{Return Loss Parameter}

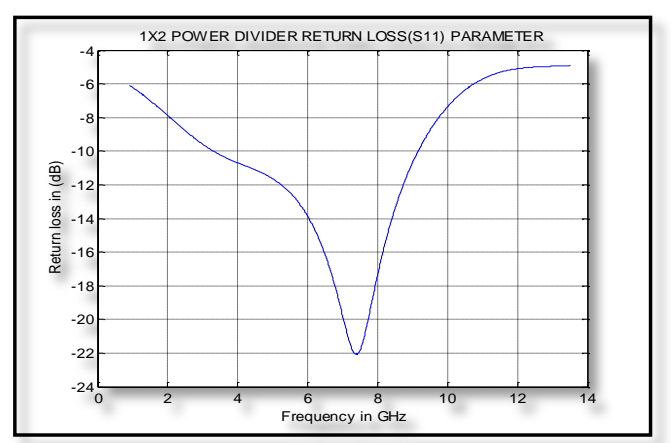

Fig. 21: Validation of Return loss parameter of proposed $1 \mathrm{X} 2$ power Divider of FR4 material

\subsection{Insertion Loss Parameter}

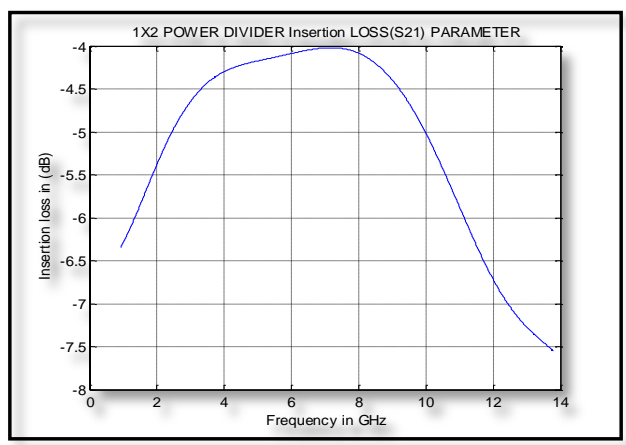

Fig. 22: Validation of Insertion loss parameter of proposed $1 \mathrm{X} 2$ power Divider of FR4 materia

\subsection{Isolation Loss Parameter}

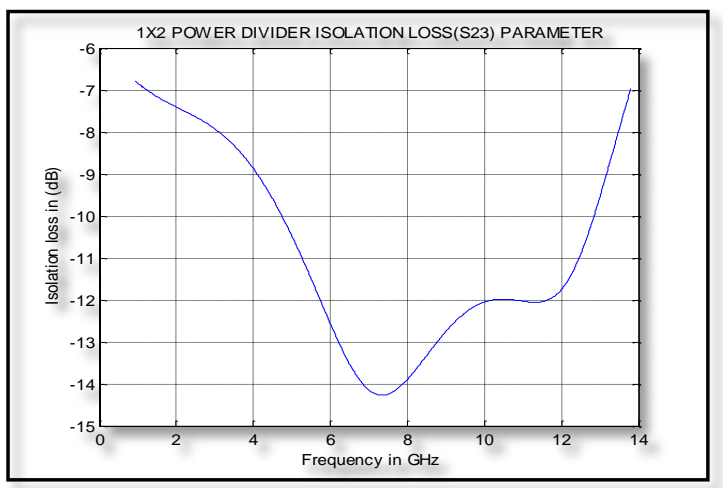

Fig. 23: Validation of Insertion loss parameter of proposed $1 \mathrm{X} 2$ power Divider of FR4 material

\section{H. Validation of Proposed 1X4Power Divider Parameters}

\subsection{Return Loss Parameter}

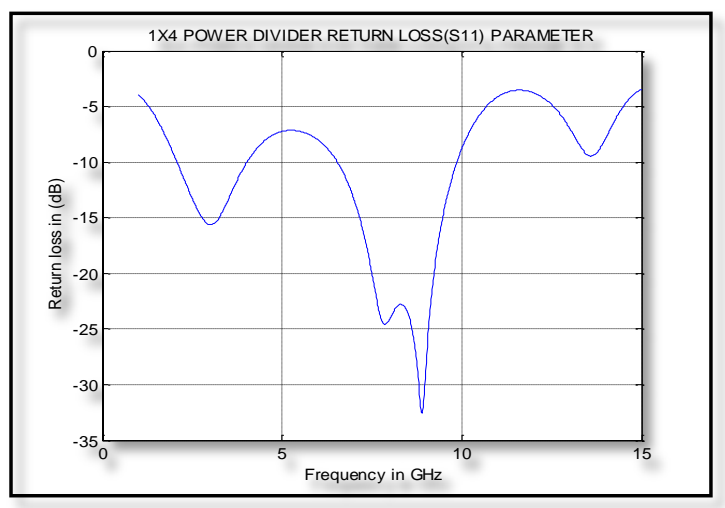

Fig 24: Validation of Return loss parameter of proposed $1 \mathrm{X} 4$ power Divider of FR4 material

\subsection{Insertion Loss Parameter}

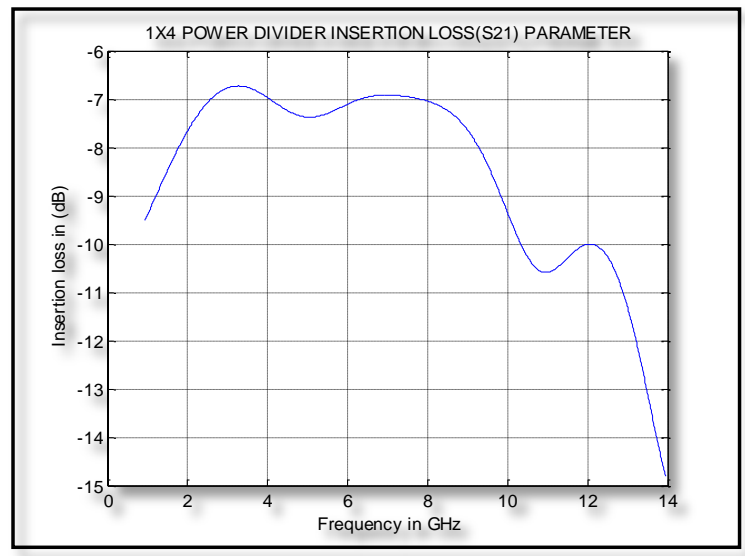

Fig. 25: Validation of Insertion loss parameter of proposed 1X4 Power Divider of FR4 material

\subsection{Isolation Loss Parameter}




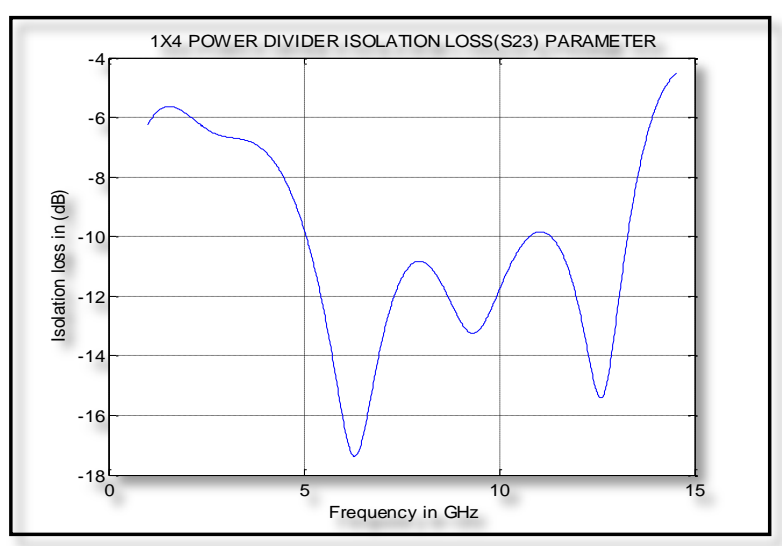

Fig.26: Validation of Insertion loss parameter of proposed 1X4 Power Divider of FR4 material

\section{I Array Implementation Using 1X2 Power Divider} Results

\subsection{Return loss}

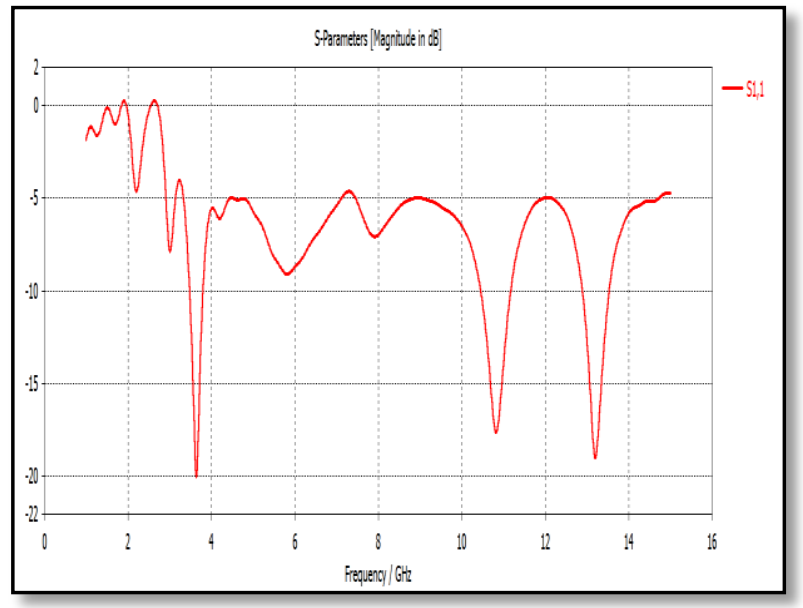

Fig.27 (a): Return loss parameter of 1X2 proposed antenna

\subsection{VSWR}

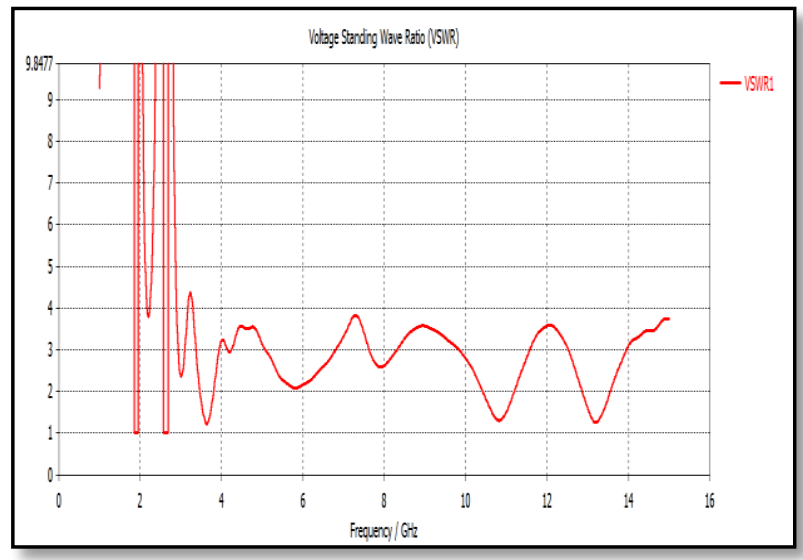

Fig. 27(b): VSWR parameter of $1 \mathrm{X} 2$ proposed antenna

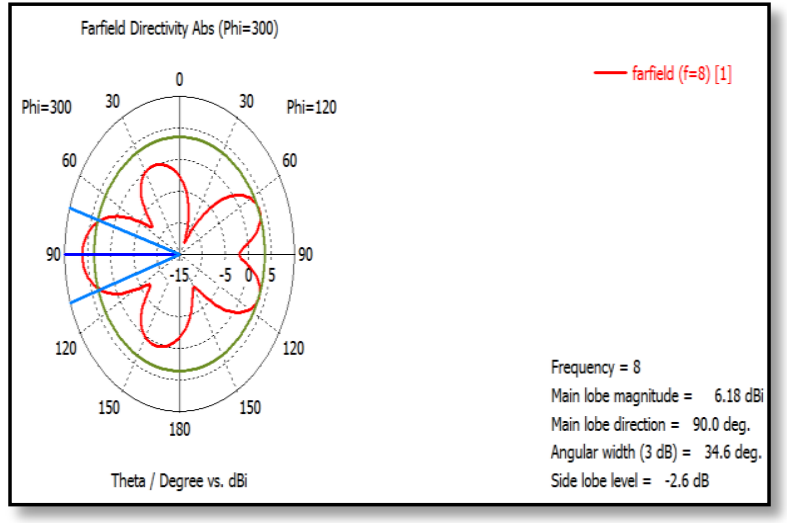

Fig. 27(c):Directivity parameter of $1 \mathrm{X} 2$ proposed antenna array

\subsection{Gain}

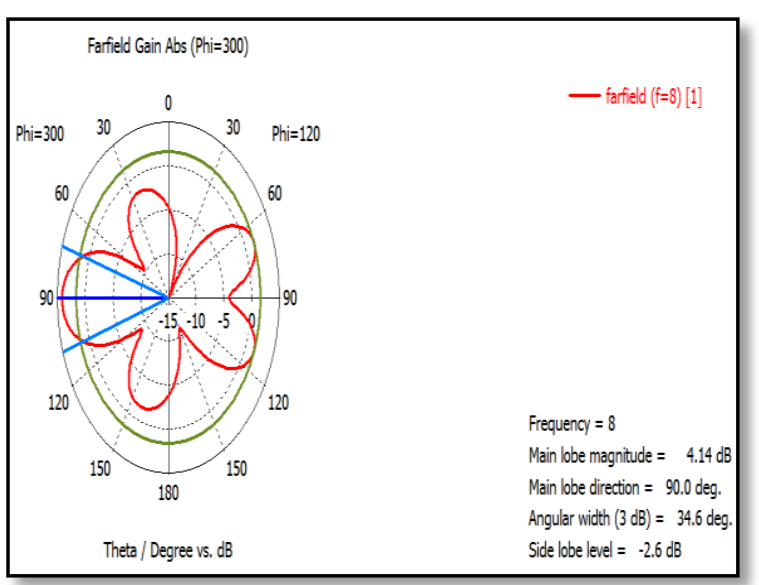

Fig. 27(d):Gain parameter of 1X2 proposed Antenna array

\subsection{Radiation Pattern}

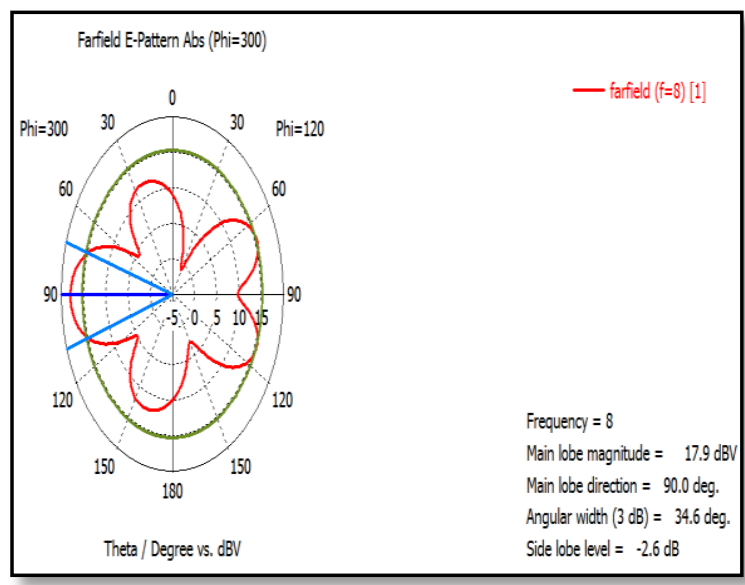

Fig.27 (e): Radiation parameter of $1 \mathrm{X} 2$ proposed Antenna array

\section{3. j.Array Implementation Using 1X4 Power Divider Results}

\subsection{Return loss}

\subsection{Directivity}




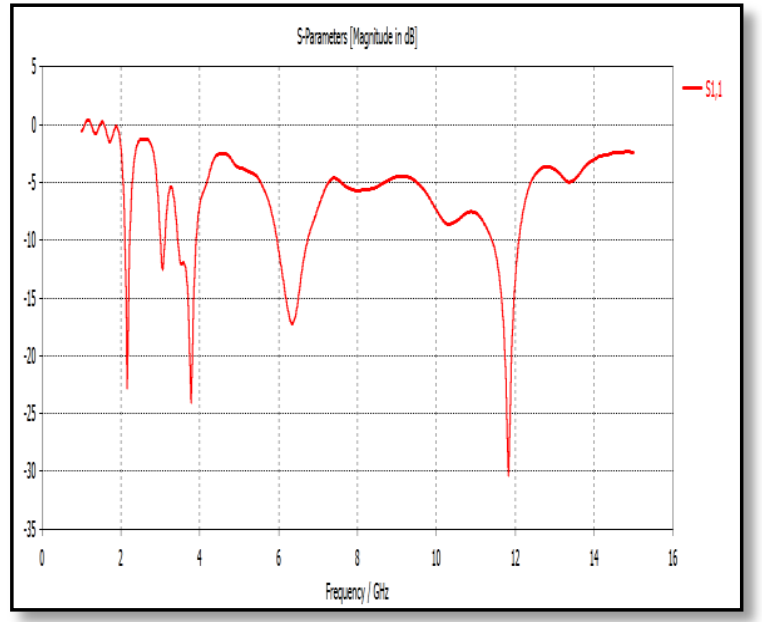

Fig. 28(a): Return loss parameter of $1 \mathrm{X} 4$ proposedAntenna array

\subsection{VSWR}

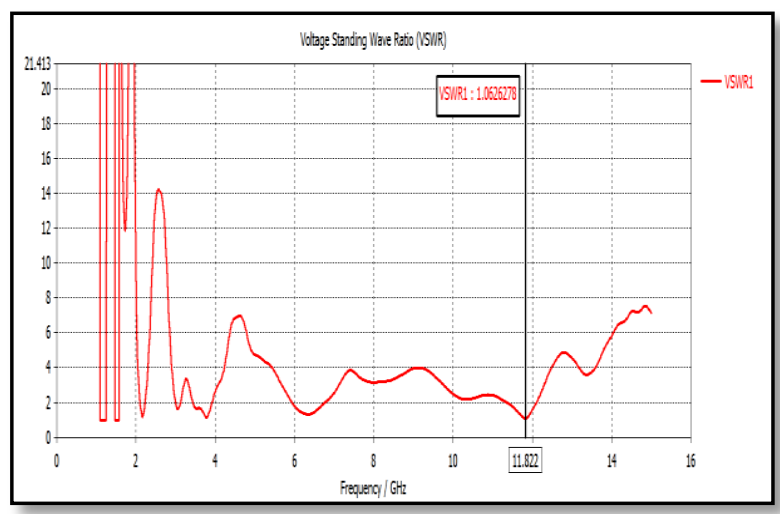

Fig. 28(b):VSWR parameter of 1X2proposedAntenna array

\subsection{Directivity}

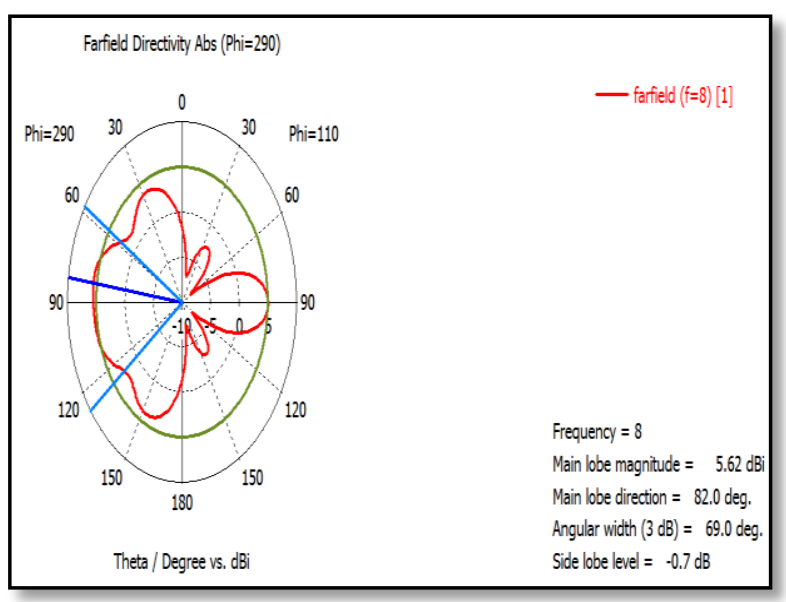

Fig. 28(c): Directivity parameter of $1 \mathrm{X} 2$ Proposed Antenna array

\subsection{Gain}

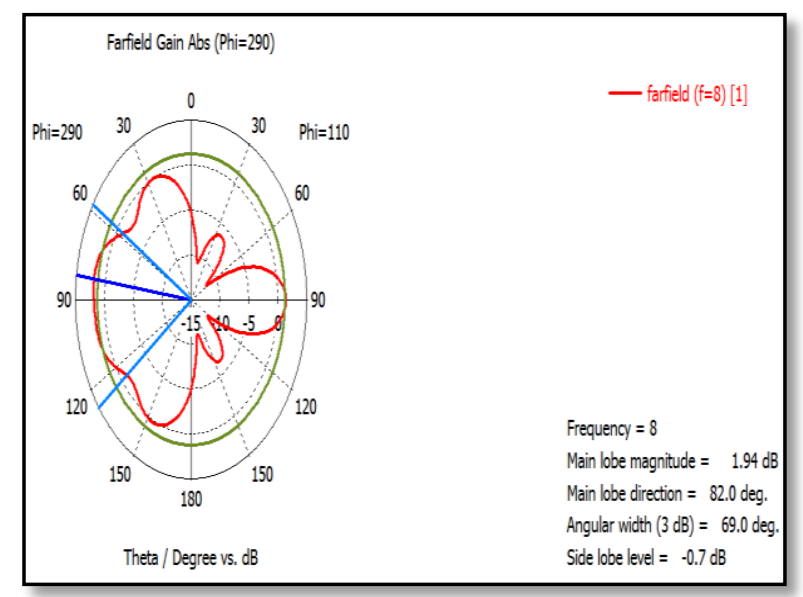

Fig. 28(d):Gain parameter of $1 \mathrm{X} 2$ proposed antenna array

\subsection{Radiation Pattern}

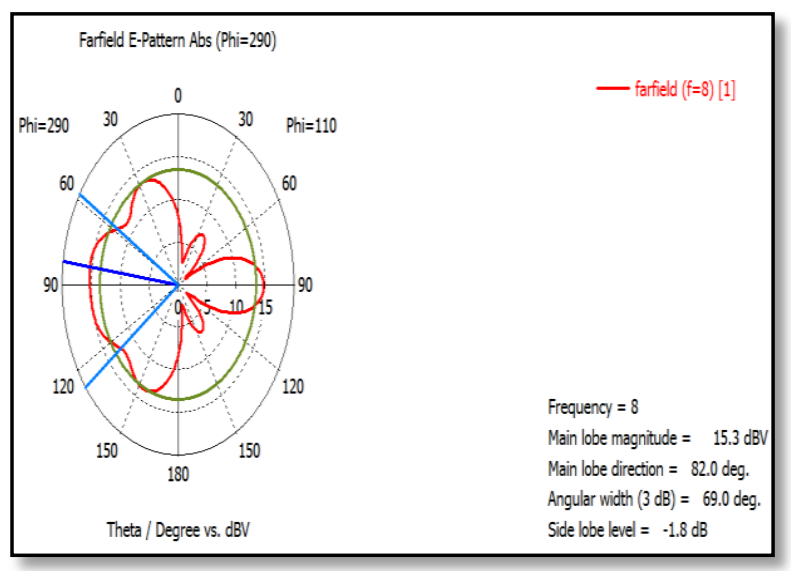

Fig. 28(e):Radiation parameter of $1 \mathrm{X} 2$ proposed Antenna array

\section{3.k. Optimization Results 1X2 Array antenna with Power divider}

\subsection{Directivity}

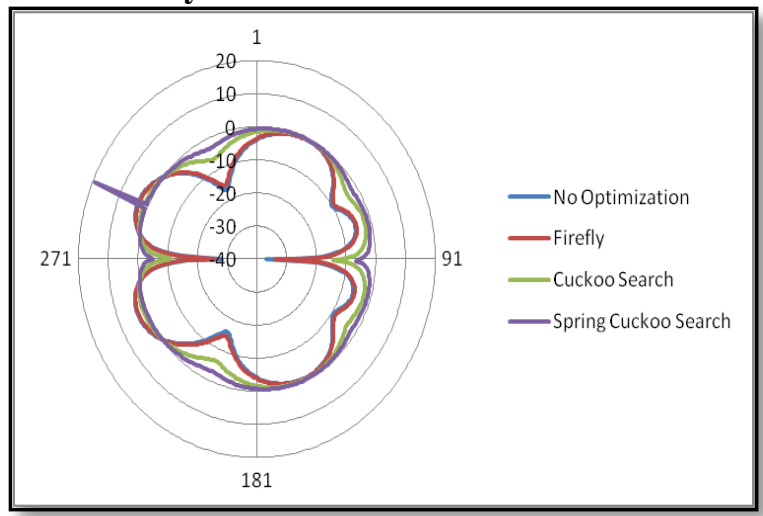

Fig.29 (a): Directivity of 1X2 Array antenna withPower divider

\subsection{Gain}




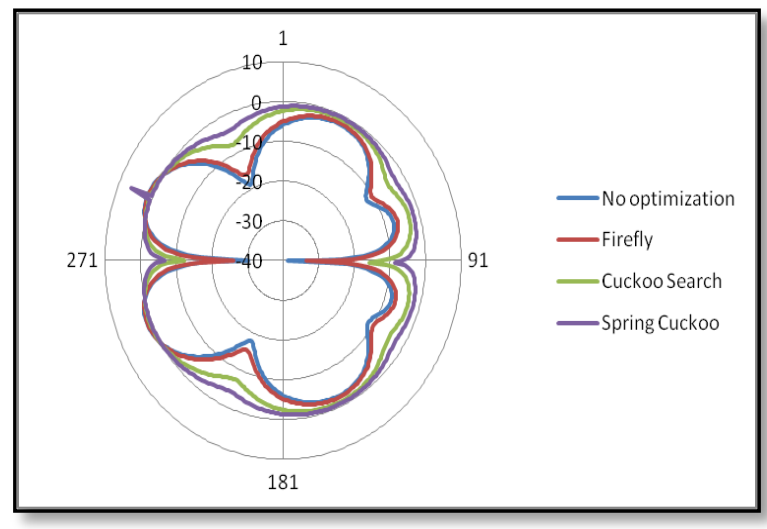

Fig.29 (b): Gain of 1X2 Array antenna with Power divider

\subsection{Radiation Pattern}

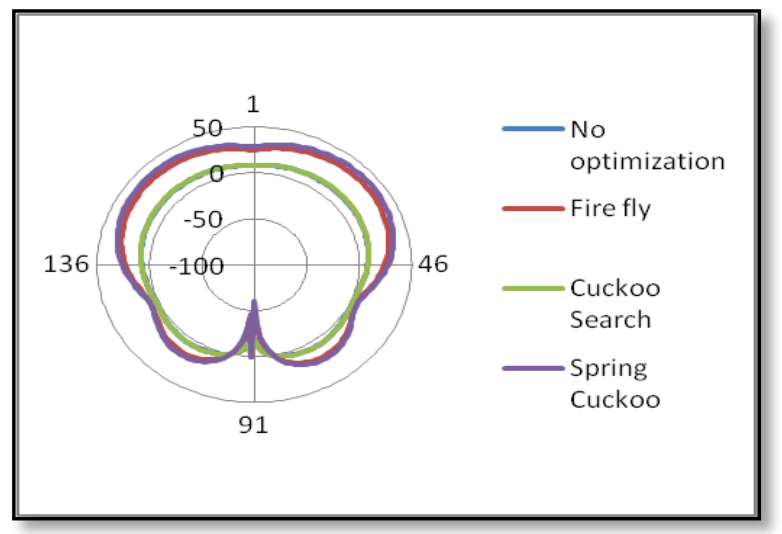

Fig.29(c):Radiation pattern of $1 \mathrm{X} 2$ Array antenna with

Power divider

\subsection{Return Loss}

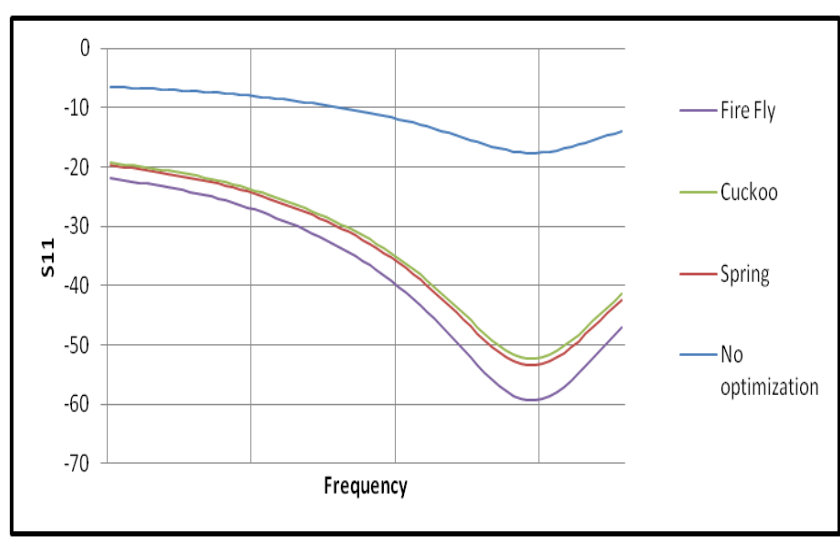

Fig.29 (d): Return loss of 1X2 Array antenna withPower divider

\section{3. l. Optimization Results 1X4 Array Antenna with} Power Divider

\subsection{Directivity}

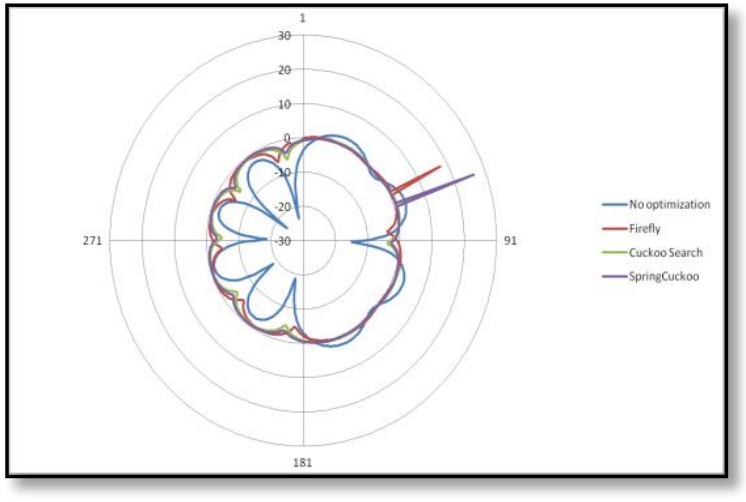

Fig.30 (a):Directivity of 1X4 Array antenna withPower divider

\subsection{Gain}

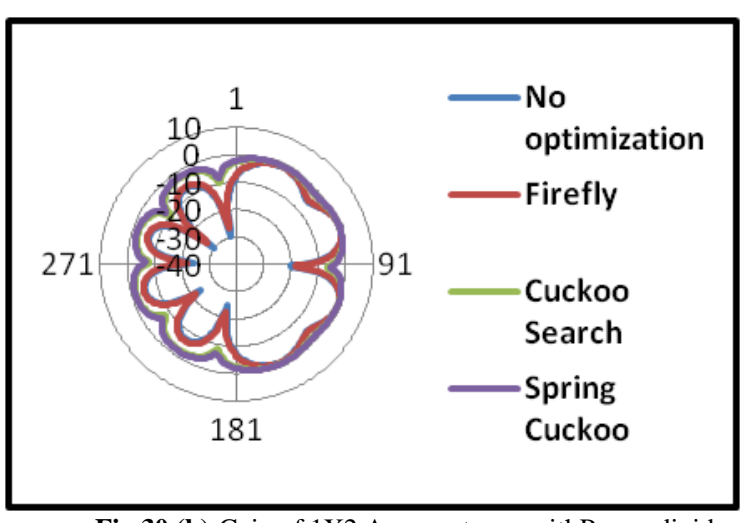

Fig.30 (b):Gain of 1X2 Array antenna withPower divider

\subsection{Radiation Pattern}

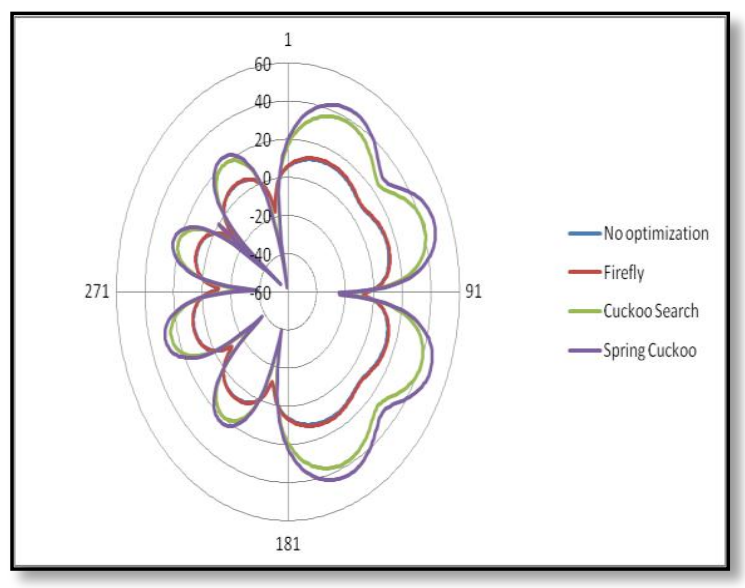

Fig.30(c):Radiation pattern of $1 \mathrm{X} 2$ Array antenna withPower divider

\subsection{Return Loss}

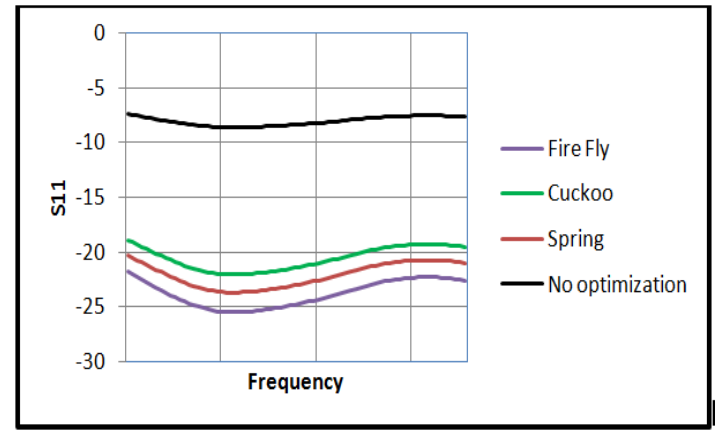

Fig.30 (d): Return loss of 1X4 Array antenna with Power divider 


\section{Conclusion}

In this paper a proposed CPW fed co-planner UWB antenna and their array system is introduced. The planned antenna array structure consists of two main parts, the antenna array, and its feeding network. A novel design for the Wilkinson power divider (the feeding network) is introduced to provide equal power division between output ports. The prototype or the power divider and the antenna array is dine using thin film technology and photolithographic technique. A $1 \mathrm{X} 2$ and $1 \mathrm{X} 4$ power divider has been designed at UWB band frequency range that depends on the Wilkinson topology. This topology has two phases: the primary stage is a $1 \mathrm{X} 2$ power divider and the $1 \mathrm{X} 4$ power divider in the second stage has been deployed in the FR4 substrate. The 1X2 and $1 \mathrm{X} 4$ power divider have been designed, fabricated and simulated with parameter insertion loss, return loss and isolation loss are presented. Insertion loss of $1 \mathrm{X} 2$ power divider is below $-3.5 \mathrm{~dB}$ and $1 \mathrm{X} 4$ power divider is below $-7 \mathrm{~dB}$ for a frequency range of $3.1-10.6 \mathrm{GHz}$, return loss of $1 \mathrm{X} 2$ power divider is $-24.668 \mathrm{~dB}$ at a frequency of $8.1849 \mathrm{GHz}$ is achieved, and $1 \mathrm{X} 4$ power divider is $36.1725 \mathrm{~dB}$ at a frequency of $8.896 \mathrm{GHz}$ is achieved, isolation less than $-15.3434 \mathrm{~dB}$ at a frequency of $7.986 \mathrm{GHz}$ for $1 \mathrm{X} 2$ power divider and $-19.3127 \mathrm{~dB}$ at a frequency of $6.474 \mathrm{GHz}$ for $1 \mathrm{X} 4$ power divider is achieved. The simulation of the system is performed using both MOM based CST Microwave Studio and MATLAB. Here using firefly algorithm, cuckoo search algorithm, spring cuckoo search algorithm are used, in this three algorithms spring cuckoo give better results among three algorithms. The experimental measurements are done using the vector network analyzer. Finally all the simulated and measured outcomes coincide with the measured results.

\section{Acknowledgment}

The authors like to convey their thanks to the department of ECE and the management of $\mathrm{K} \mathrm{L}$ University for their support and encouragement during this work

\section{References:-}

[1] Chien-Hung Chen, Ching-Yun Wu, Chien-Ching Chiu, Shu-Han Liao "A multi-objective optimization for UWB antenna array in indoor environment" 978-1-4673-6361-7/13@2013 IEEE

[2] Xin-She Yang, Suash Deb, "Engineering Optimisation by Cuckoo Search" Int. J. Mathematical Modelling and Numerical Optimisation, Vol. 1, No. 4, pp.330-343 (2010).

[3] K. RajKamal, Govardhani Immadi "A Compact Uwb Micro Strip Patch Antenna Using Coplanar Wave Guide Feeding For Bio Medical Applications" ARPN Journal of Engineering and Applied Sciences, VOL. 13, NO. 3, FEBRUARY 2018

[4] K. Rajkamal, Dr. I.Govardhani "Miniaturized Ultra Wideband Planar Wilkinson Power Divider" International Journal of Pure and Applied Mathematics, Volume 117 No. 18 2017, pp.135-141

[5] Xing-Ping Ou, Qing-Xin Chu "A Modified Two-section UWB Wilkinson Power Divider" 978-1-4244-1880-0/08 (C2008 IEEE.

[6] Ammar H. Ali, Raed A. Abd-Alhameed,James M. Noras and Mark B. Child "An Ultra Wide Band Power Divider for Antenna Array Feeding Network" Loughborough Antennas \& Propagation Conference (LAPC), 2016, 978-1-5090-0783-7/16@2016 IEEE

[7] Amr H. Hussein, Mohamed A. Metawe'e,Haythem H. Abdullah, "Hardware implementation of antenna array system for maximum SLL reduction" Engineering Science and Technology, an International Journal 20 (2017),pp. 965-972

[8] Osama Ahmed , A. R. Sebak, "A Modified Wilkinson Power Divider/Combiner for Ultra wideband Communications" 978-14244-3647-7/09 (2009 IEEE

[9] Bo Zhou, Hao Wang, Weixing Sheng "A Novel UWB Wilkinson Power Divider" 978-1-4244- 7618-3 /10 @2010 IEEE

[10] Jafargholi, M. Kamyab, "Pattern Optimization In An Uwb Spiral ArrayAntenna" Progress In Electromagnetics Research M, Vol. 11, $137-151,2010$
[11] AbdolmehdiDadgarpour, GholamrezaDadashzadeh, Mohammad Naser-Moghadasi, "PSO/FDTD Optimization Technique for Designing UWB In-Phase Power Divider for Linear ArrayAntenna Application", IEEE Antennas And Wireless Propagation Letters, VOL. 9, 2010

[12] B. Kasi, C.K. Chakrabarty, "Ultra-Wideband Antenna Array Design Fortarget Detection", Progress In Electromagnetics Research C, Vol. 25, 67-79, 2012

[13] L. Chang,C.Liao,L.-L.Chen,W.B.Lin,X. Zheng, Y.-L.Wu, "Design Of An Ultra-Wideband Power Divider Via The Coarse-Grained Parallel Microgenetic Algorithm" Progress In Electromagnetics Research, Vol. 124, 425-440, 2012

[14] R. Gholami, B. Zakeri, H. MehrpourBernety, "Design and Analysis of New Ultra-Wideband Linear Antenna Array for Wireless Applications", Amirkabir International Journal of Science\& Research, Vol. 44, No. 2, Fall 2012, pp. 11- 19

[15] Liang Liu, RonghongJin, Hangchen Yu, Xianling Liang, JunpingGeng, Xudong Bai, "A Compact Ultra-Wideband Power Divider with High Isolation” 978-1-4799-3540-6/14/\$31.00 @2014 IEEE

[16] Yanfang Wang, Fuguo Zhu, Steven Gao, "Design and Implementation of Connected Antenna Array for Ultra-Wideband Applications", Progress In Electromagnetics Research C, Vol. 58, 79-87, 2015

[17] SUMANI, S.D. BENNANI, A. EL ALAMI, H. HARKAT, "Optimization Parameters of Ultra Wide band Microstrip Array Antenna for Wireless Communication using Beam Steering” 978-14673-8096-6115@2015, IEEE

[18] Wei Chien, Chien-Ching Chiu, Sung-Shiou Shen ,Tsai-Hua Kang, "Multi-objective optimization for UWB antenna array by GA algorithm", Proceedings of the IEEE International Conference on Advanced Materials for Science and Engineering IEEE-ICAMSE 2016 - Meen, Prior \& Lam (Eds)

[19] Osama Dardeer, Tamer Abouelnaga, Ashraf Mohra, HadiaElhennawy, "Compact UWB Power Divider, Analysis and Design" Journal of Electromagnetic Analysis and Applications, 2017, 9, 9-21

[20] K.Rajkamal, Govardhani.Immadi, "Design And Analysis Of Different Substrate Materials For Uwb Antenna Used For Biomedical Applications", Journal of Theoretical and Applied Information Technology, $15^{\text {th }}$ April 2018. Vol.96. No 7, pp-20152024

[21] K.Rajkamal, Govardhani.Immadi, "Design And Analysis Of Modified Wilkinson Equal Power Divider For Ultra Wide Band Applications (3.1-10.6 Ghz)", Journal of Advanced Research in Dynamical and Control Systems Vol. 9. Sp-17/2017

\section{Author Biography:}

K.RAJKAMAL was born in ANDHRAPRADESH, INDIA, 1989. He completed B.Tech Degree in Loyola institute of technology and management affiliated to JNTUKAKINADA, A.P, INDIA in 2010. He completed M.Tech Degree in K L University, A.P, INDIA in 2012. Now he is pursuing Doctoral Degree in K L University, A.P, INDIA. His interested areas are antennas, Microwave and communications.

Govardhani.Immadi: was born in andrapradesh India in the year 1983, received B.Tech in the year 2004 from KLCE affiliated to acharya nagarjunauniversity.completdMasetrs degree in the year 2009.received $\mathrm{PhD}$ from KLUniversity in the 2015. Research areas are Satellite communication, Microwaves and Antennas. 